\title{
Laser-Based Lithography for Polymeric Nanocomposite Structures
}

\author{
Athanassia Athanassiou, Despina Fragouli, \\ Francesca Villafiorita Monteleone, Athanasios Milionis, \\ Fabrizio Spano, Ilker Bayer and Roberto Cingolani \\ Center for Biomolecular Nanotechnologies@UNILE, \\ Istituto Italiano di Tecnologia (IIT), Via Barsanti, 73010 Arnesano, Lecce
}

Italy

\section{Introduction}

In recent years, the synthesis of polymeric nanocomposites has gained much interest in the scientific community thanks to their unique capability to combine the properties of the host polymer matrices, such as toughness, elasticity, processability, solubility, thermal stability, etc, with those of inorganic nanoparticles (NPs), such as hardness, chemical resistance, optical and electronic properties. Among a variety of nanofillers, semiconductor and metallic NPs are extensively studied and used, because of their unique properties especially in the nanoscale. In this work we deal with polymeric nanocomposites incorporating various nanofillers, each one of them having extremely attractive properties for technological applications. In particular we focus on titanium dioxide $\left(\mathrm{TiO}_{2}\right) \mathrm{NPs}$ due to their unique reversible wettability, iron oxide $\left(\mathrm{Fe}_{2} \mathrm{O}_{3}\right)$ NPs due to their superparamagnetic nature, gold $(\mathrm{Au}) \mathrm{NPs}$ due to their enhanced electronic conductivity, and cadmium sulphide (CdS) NPs due to their tuned photoemission in the quantum size regime.

Nanocomposite materials are usually prepared by simple blending of the nanosized inorganic components into polymer solutions. Nevertheless, this method quite often leads to formation of aggregates or macroscopic phase separation, since the control of the dispersion and distribution of the nanofillers within the organic matrices is impossible. To obtain a higher compatibility between the filler and the host polymeric material, and achieve coatings with high content of inorganic particles, the use of polymerization techniques is widely adopted (Fouassier 1995, Decker et al 2005, Lee et al 2006, Wang \& Ni 2008). From this point of view, several methods can be considered, depending on the type of monomers and nanomaterials, such as bulk polymerization, photoinitiated polymerization, emulsion polymerization, in situ thermal polymerization, or copolymerization in solution. Among them, the use of ultraviolet (UV) light in combination with proper photoinitiators to produce polymeric nanocomposite films is one of the most rapid and effective method, the main advantage being the creation of well defined patterned structures.

Patterning of nanocomposites using UV polymerization, the so-called UV photolithography is ideal for the direct incorporation of nanocomposites into specific parts of systems and devices. Photolithographically prepared nanocomposite structures can be used for the selective deposition of molecules, which have specific affinity to the photopolymerized 
material, for the creation of molecular sandwiches, for cells deposition, for microfluidic devices, sensors, photoemitting parts in devices, etc. Herein, we present two different UV light-based lithography techniques for formation of nanocomposite patterns that consist of polymers incorporating inorganic nanofillers. The latter are either colloidal NPs produced by chemical synthesis, or NPs that are formed directly into the polymer matrices starting from an appropriate precursor, using laser light irradiation.

In particular the photolithography presented in this work follows two approaches:

1. UV laser photopolymerization: the nanocomposite solutions preexist in the form of colloidal NPs mixed with monomers and photocuring agent and laser light beams induce the patterned structures. Three systems are demonstrated: $\mathrm{PMMA}$ with $\mathrm{TiO}_{2}$ NPs, PMMA with $\mathrm{Fe}_{2} \mathrm{O}_{3}$ NPs, SU-8 with $\mathrm{Fe}_{2} \mathrm{O}_{3}$ NPs. In the last two systems we can induce further nanopatterning into the patterned polymers structures using an external magnetic field to align the nanofillers into nanowires (NWs).

2. UV laser light-induced formation of NPs into polymers: the starting system is a polymeric film incorporating light-sensitive precursors of NPs and laser light irradiation induces the formation of NPs in specific locations in the polymer matrix. Three systems are demonstrated: Chitosan with Au NPs, TOPAS with CdS NPs, PMMA with CdS NPs.

The patterns of nanocomposites produced with the above mentioned lithography methods are categorized according to their properties as follows: patterns with tunable surface properties, magnetic patterns, conducting patterns, patterns with tunable emission. Such patternable composite materials deal with most of the present technologies, including bioengineering and medical instrumentation, packaging, electrical enclosures, sensors, actuators and energy.

\section{Lithography using laser photopolymerization}

Lithographic patterning using UV light in combination with monomers and appropriate photoinitiators is a very attractive technology due to low energy consumption, room temperature operation, rapid curing, spatial control, possibility of curing structures on heatsensitive substrates etc. (Andrzejewska 2001). The use of the specific technique for lithography of nanocomposites, permits to realize materials with homogeneous dispersion of the inorganic phase, but also to simultaneously create patterned surfaces in an easy and single step. (Sun et al 2008)

The photopolymerization technique involves UV/visible light absorption from the photoinitiators forming radical species (initiation reaction), which are responsible for the initiation of the photopolymerization process due to their addition to the monomer molecules (propagation reaction). The chain growth termination occurs upon annihilation of the radical centres due to radical-radical recombination (termination reaction). Among different light sources, lasers are most widely used when lithography is involved due to their unique characteristics that lead to small, highly controlled, sharp and precise patterns. In the presented work a pulsed laser was used permitting high energy concentrations in very short times, and allowing polymerization to develop to a high extent in the dark periods between consecutive pulses (Van Herk 2000).

\section{$2.1 \mathrm{TiO}_{2}$-based patterned nanocomposites}

In the development of polymeric nanocomposites, semiconductor oxides are extensively studied and applied as nanofillers due to their unique electromagnetic, mechanical, 
chemical and numerous other properties. In particular, among them titanium dioxide $\left(\mathrm{TiO}_{2}\right)$ is possibly the most widely used, thanks to two exceptional properties: the photocatalytic activity and the reversible wettability, both activated upon UV irradiation (Fujishima 2000, Nakajima 2000, 2001, Wang 1997, 1998, 1999, Sakai, 1998, 2001, 2003).

In this section we focus on the reversible wettability properties of $\mathrm{TiO}_{2}$ upon excitation with UV laser light. Specifically, nanorods (NRs) of $\mathrm{TiO}_{2}$ are used as the basic building blocks of photolithographically patterned nanocomposite materials with functional and responsive surfaces, which show UV-sensitive wettability. It has been demonstrated that upon UV irradiation of $\mathrm{TiO}_{2}$, oxygen vacancies are created on its surface resulting into the conversion of $\mathrm{Ti}^{4+}$ into $\mathrm{Ti}^{3+}$ sites. These sites are favourable for dissociative adsorption of atmospheric water molecules, leading to the formation of a highly hydroxylated (hence, hydrophilic) surface. This procedure is reversible, since upon long term storage (few months) under ambient dark conditions, or for an accelerated process, upon thermal treatment, vacuum storage or visible irradiation (Wang et al., 1999, Nakajima et al., 2001, Sakai et al., 1998), the adsorbed hydroxyl groups can be removed and eventually replaced by ambient oxygen, allowing the initial hydrophobicity to be recovered (Caputo et al., 2008). Taking advantage of the above described mechanism we present herein how the formed $\mathrm{TiO}_{2}$ /polymer nanocomposite patterns can serve as paths for the directional movements of water drops onto them.

\subsubsection{Photopolymerized patterns of $\mathrm{PMMA} / \mathrm{TiO}_{2}$}

Solutions of MMA monomer, $\mathrm{TiO}_{2} \mathrm{NRs}$, and photoinitiator were prepared in toluene to obtain concentrations of $94 \mathrm{wt} . \%, 5 \mathrm{wt} . \%$ and $1 \mathrm{wt} . \%$, respectively. The photoinitiator was the IRGACURE®1700. It is formed by two distinct molecules, a phosphine oxide derivative and a hydroxyl alkyl phenyl ketone, which acts as co-initiator. Upon UV irradiation, electrons and hydrogen atoms are transferred from the co-initiator molecules to the photoinitiator, generating radicals that initiate the polymerization of the methyl methacrylate (MMA) monomers. All the solutions were stirred and left under dark for several minutes to equilibrate. Glass and silicon substrates were washed with isopropanol and subsequently with acetone and dried with nitrogen. About $200 \mu \mathrm{L}$ of each solution were initially spin coated on both glass and silicon substrates at $1000 \mathrm{rpm}$ for $20 \mathrm{~s}$. Next, about 40 $\mu \mathrm{L}$ of the same solution were drop casted onto each sample.

To obtain photopolymerization, the third harmonic of a pulsed Nd:YAG laser (Quanta-Ray GCR-190, Spectra Physics, energy density $=10.5 \mathrm{~mJ} \cdot \mathrm{cm}^{-2}, \lambda=355 \mathrm{~nm}$, pulse duration $=6 \mathrm{~ns}$, repetition rate $=10 \mathrm{~Hz}$ ) was used. In particular, the previously casted samples were irradiated through aluminum masks characterized by different patterns of mm-dimensions. After the photopolymerization, each sample was washed 3 times with methanol to remove unreacted monomer and photoinitiator, and then dried in ambient dark conditions. In Figure 1 are demonstrated characteristic patterns created upon UV laser irradiation of the drop casted solution through a photomask of two parallel lines in the $\mathrm{mm}$ range, demonstrating the potentiality of the specific lithography technique.

A closer look of the surfaces of the photolithographically produced nanocomposite patterns shown in Figure 1 was performed using lateral force Atomic Force Microscopy (AFM). The obtained AFM images demonstrate that NRs are apparent onto the surface of the photopolymerized $\mathrm{MMA}^{-\mathrm{TiO}_{2}}$ nanocomposite films. In general, they appear quite aggregated, however it is occasionally possible to distinguish also single NRs laying parallel to the substrate (Figure 2a). In contrast, the photopolymerized coatings without $\mathrm{TiO}_{2} \mathrm{NRs}$ appear flat and homogeneous under the AFM (Figure 2b). 


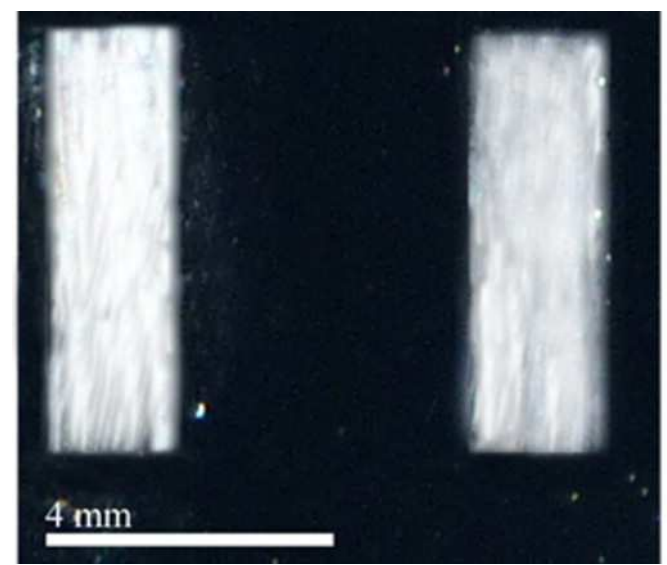

Fig. 1. Photolithographically created lines of mm-dimensions of $\mathrm{PMMA} / \mathrm{TiO}_{2} \mathrm{NRs}$ nanocomposites.
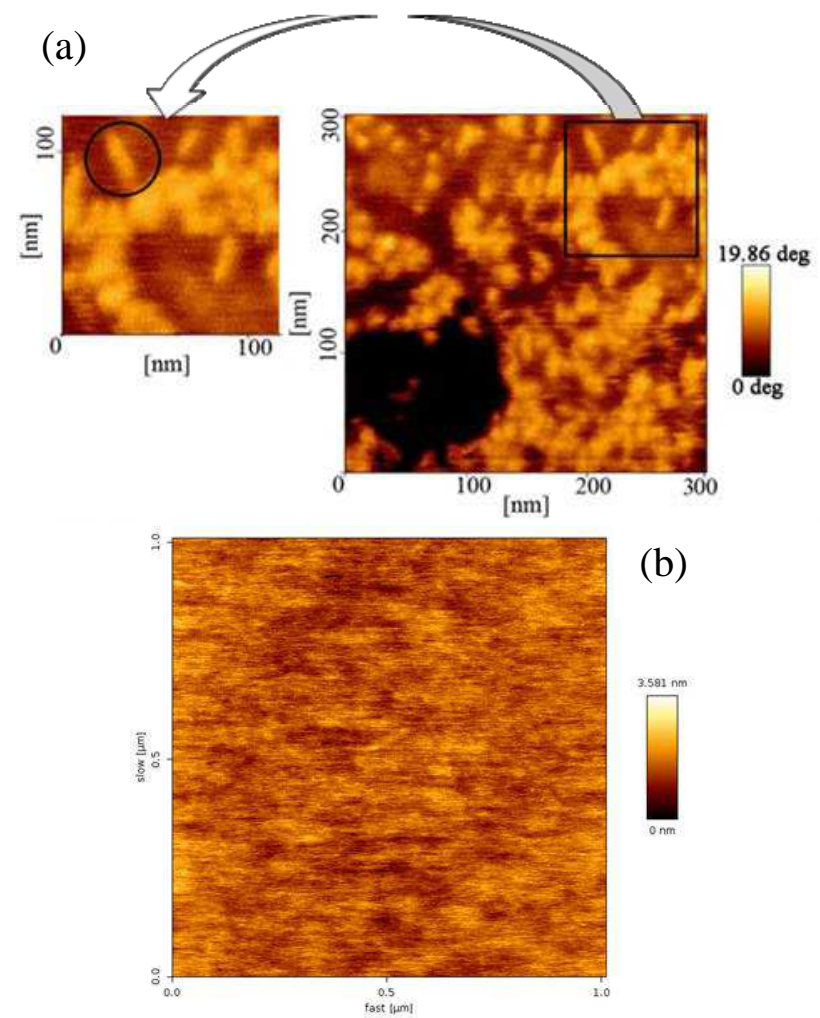

Fig. 2. AFM images of (a) photolithographically produced nanocomposite patterns demonstrating NRs onto their surface, and of (b) photopolymerized coatings of PMMA without $\mathrm{TiO}_{2}$ NRs. 
In order to enhance the hydrophilicity of the $\mathrm{TiO}_{2}$ NRs exposed on the surface of the photopolymerized nanocomposites, the prepared patterns were irradiated for diverse time intervals with a pulsed Nd:YAG laser at $355 \mathrm{~nm}$ (energy density $=7 \mathrm{~mJ} \cdot \mathrm{cm}^{-2}$, repetition rate $=10 \mathrm{~Hz}$, pulse duration $\sim 4-6 \mathrm{~ns}$ ). Increasing irradiation time up to $90 \mathrm{~min}$ under the specific experimental conditions, increases the hydrophilicity of the nanocomposites' surfaces (Villafiorita Monteleone et al 2010). The complete recovery of the initial wettability of the films was achieved by placing them in vacuum at a pressure of $3 \cdot 10^{-3}$ mbar for 48 hours. We take advantage of the controlled wettability changes to realize liquid flow paths, irradiating adjacent surface areas of the photolithographically produced lines of nanocomposites with increasing time, and creating wettability gradients along their surfaces, essential for liquid droplet motion. An example is demonstrated in Figure 3, where is shown a $X \times Y=6 \times 1 \mathrm{~mm}^{2}$ laser photopolymerized nanocomposite film, where in order to achieve the drop movement along the $X$-axis, a first area of $\mathbf{X x Y}=\mathbf{1} \mathbf{x} \mathbf{1} \mathbf{m m}^{2}$ was left without irradiation, the next $\mathbf{X x Y}=$ $\mathbf{1 x} \mathbf{1} \mathrm{mm}^{2}$ area was irradiated for $20 \mathrm{~min}$ and two adjacent areas of $\mathbf{X x Y}=\mathbf{2} \times \mathbf{1} \mathrm{mm}^{2}$ each, were irradiated for 40 and $90 \mathrm{~min}$, respectively. The spontaneous water drop movement occurs as shown at the right hand side of Figure 3 (Figure 3c) because the following criteria essential for the movement are fulfilled: (1) The contact angle hysteresis $\left(\Delta \theta_{h}\right)$ of the rear area, irradiated for less time must be smaller than the difference between the advancing contact angles of the two adjacent areas (nominated $\Delta \theta$ in Figure 3). (2) The side of each irradiated area along the direction of the movement should be smaller than the diameter of the drop on

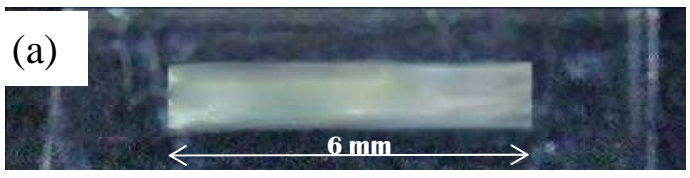

(b)

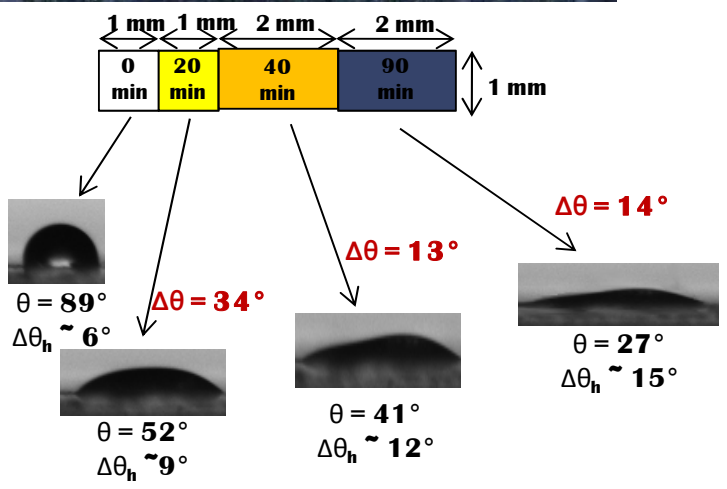

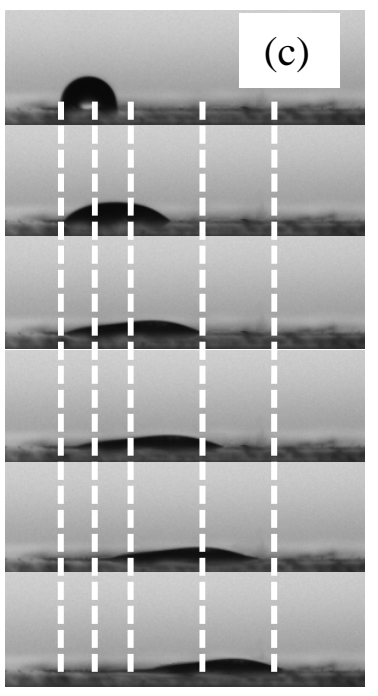

Fig. 3. (a) Photolithographically created line of dimensions $6 \times 1 \mathrm{~mm}^{2}$, of $\mathrm{PMMA} \mathrm{TiO}_{2} \mathrm{NRs}$ nanocomposite. (b) Graphical representation of the dimensions of the adjacent irradiated areas together with the irradiation times on each area. The pictures of the water drops obtained on each area with their water contact angle and hysteresis values and the difference between the advancing contact angles of the two adjacent areas are also shown. (c) Side view photographs of a water droplet that is moving on the $\mathrm{PMMA}_{\mathrm{TiO}}$ surface with UV-induced gradient hydrophilicity. The hydrophilicity increase is in the direction of the drop movement, from left to right. 
the specific area, so that the front edge of the drop is always in contact with a more hydrophilic area than the back edge (Villafiorita Monteleone et al., 2010). This kind of samples are very versatile and can be used as described above or incorporated in more complicated systems and devices, such as microfluidics, labs on chip etc.

\section{$2.2 \mathrm{y}-\mathrm{Fe}_{2} \mathrm{O}_{3}$-based patterned nanocomposites}

Magnetic particles are useful in different biomedical applications, such as magnetically induced hyperthermia of malignant tumors, contrast enhancement agents for magnetic resonance imaging (MRI), tissue repair (Gupta et al 2005, Pankhurst et al 2003), and delivery of drugs (Voltairas et al 2002) or nucleic acids (Mair et al 2009, Buerli et al 2007), as they can be manipulated via external magnetic fields to improve transport in biological systems. They are also used in the fabrication of photonic crystals (Ding et al 2009), as nanowire contacts in electronic devices (Bangar et al, 2009), and as device components in microfluidics (Kavcic et al 2009; Fahrni et al 2009). Additionally, there has been growing interest in the use of magnetic particles in the fabrication of nanomotors and nanomachines (Ghosh \& Fischer, 2009).

Among all magnetic NPs, iron oxides are possibly the most frequently used, due to their high magnetic moment, chemical stability, low toxicity, biocompatibility, easy and economical synthetic procedures. Iron oxides exist in many forms in nature, with magnetite $\left(\mathrm{Fe}_{3} \mathrm{O}_{4}\right)$, maghemite $\left(\gamma-\mathrm{Fe}_{2} \mathrm{O}_{3}\right)$ and hematite $\left(\mathrm{a}-\mathrm{Fe}_{2} \mathrm{O}_{3}\right)$ being the most common (Cornell \& Schwertmann 2003). Magnetite is ferrimagnetic at room temperature (Cornell \& Schwertmann 2003), and usually particles smaller than $\approx 6 \mathrm{~nm}$ are superparamagnetic at room temperature, although their magnetic properties depend strongly on the methods used in their synthesis (Kado 2008, Zhao et al 2007). At room temperature, maghemite is ferrimagnetic while particles smaller than $\approx 10 \mathrm{~nm}$ are superparamagnetic (Neuberger et al 2005). Aggregation of ultrafine maghemite particles sometimes leads to their magnetic coupling and ordering of their magnetic moment, which is termed superferromagnetism (Cornell \& Schwertmann 2003). Hematite is paramagnetic at temperatures above $956 \mathrm{~K}$. At room temperature, it is weakly ferromagnetic and undergoes a phase transition at $260 \mathrm{~K}$ to an antiferromagnetic state. The magnetic behavior of hematite depends also on crystallinity, particle size and on the extent of cation substitution (Cornell \& Schwertmann 2003).

The magnetic properties of iron oxides have been exploited in a broad range of applications including magnetic seals and inks, magnetic recording media, catalysts, ferrofluids, contrast agents for magnetic resonance imaging, therapeutic agents for cancer treatment, and numerous others (Azhar Uddin et al 2008, Cui et al 2006, dos Santos Coelho et al 2008). These applications demand nanomaterials of specific sizes, shapes, surface characteristics, and magnetic properties, so the specific type of iron oxide is chosen every time depending on the field of use. On the top, iron oxide in polymer matrices, forming functional nanocomposites, pave the way to novel plastic devices for gas and vapor sensing, actuation, molecular separation, electromagnetic wave absorption, nonlinear optical systems, and photovoltaic solar cells (Kaushik et al 2009, Merkel et al 2002, Huo et al 2009, Long 2005). Furthermore, the magnetic properties of iron oxide can be used in future generations of electronic, magnetic, and photonic devices for information storage or magnetic imaging (Weller et al 2000, Wang et al 2004).

For enhanced performances and occasionally directional, nanocomposite systems require high density of oriented anisotropic magnetic nanostructures, like NWs, in polymer matrices. Indeed, the realization of arrays of NWs is a new interesting solution to obtain novel collective properties, different from those of isolated NPs (Tang and Kotov, 2005). 
One-dimensional magnetic NWs can be produced by the assembly of isotropic magnetic NPs, under external magnetic field (MF). This is an attractive technique for the fabrication of NWs, due to its simplicity and at the same time, high effectiveness. In this perspective, several studies have recently demonstrated the possibility of producing oriented magnetic nanocomposites through the dispersion of magnetic NPs in polymer or prepolymer solutions, and subsequent evaporation or polymerization under a weak magnetic field (Park et al 2007, Jestin et al 2008, Fragouli \& Buonsanti et al 2010, Fragouli \& Torre et al 2010).

Here, we present photolithographically realized patterned nanocomposites of PMMA or SU8 polymers which incorporate magnetic NWs, formed starting from spherical iron oxide ( $\gamma$ $\mathrm{Fe}_{2} \mathrm{O}_{3}$ ) colloidal NPs. Indeed, applying a homogeneous magnetic field produced by two magnets to the nanocomposites solutions, NWs are formed, which are aligned along the magnetic field lines. We demonstrate that the photolithography process does not affect the NPs alignment, and, more importantly, that it allows the creation of polymeric patterns with magnetic properties in specific areas.

\subsubsection{Photopolymerized patterns of $\mathrm{PMMA} / \mathrm{Fe}_{2} \mathrm{O}_{3}$}

Solutions of methyl methacrylate (MMA) monomer mixed with colloidal $\gamma-\mathrm{Fe}_{2} \mathrm{O}_{3} \mathrm{NPs}$ in the presence of a photoinitiator IRGACURE®1700 were prepared in chloroform at concentrations of 89.5 wt. $\%, 10$ wt. $\%$ and 0.5 wt. $\%$, respectively. The $\mathrm{Fe}_{2} \mathrm{O}_{3} \mathrm{NPs}$ were previously prepared in chloroform, by modifying a wet-chemical synthetic approach previously reported (Sun et al 2004), in order to obtain hydrophobic-capped $\mathrm{Fe}_{2} \mathrm{O}_{3}$ spherical particles with a mean diameter of $10 \mathrm{~nm}$. Oleic acid, oleylamine, and hexadecane-1,2-diol were used as capping molecules of the produced NPs. All solutions were stirred and left in the dark for few minutes to equilibrate. $200 \mu \mathrm{L}$ of each solution were spin-coated at 1000 rpm for $20 \mathrm{~s}$, and subsequently $\sim 40 \mu \mathrm{L}$ of the same solution were drop-casted onto glass substrates. For the alignment of the nanoparticles, the system was subjected to a homogeneous magnetic field $(\sim 160 \mathrm{mT})$, produced by two permanent magnets, applied parallel to the substrate during the deposition, evaporation and photopolymerization processes.

The patterned $\mathrm{PMMA} / \mathrm{Fe}_{2} \mathrm{O}_{3}$ nanocomposites were obtained by irradiating all samples with the third harmonic of a pulsed Nd:YAG laser (Quanta-Ray GCR 190, Spectra Physics) with an energy density of $10.5 \mathrm{~mJ} \cdot \mathrm{cm}^{-2}(\lambda=355 \mathrm{~nm}$, pulse duration $=4-6 \mathrm{~ns}$, repetition rate $=10 \mathrm{~Hz}$ ) for 90 minutes, using aluminum photomasks with different geometries. After the photopolymerization, each sample was washed three times with methanol to remove unreacted monomer and photoinitiator and then dried under ambient dark conditions for 2 days to achieve complete solvent evaporation. In Figure 4 are demonstrated characteristic patterns created upon irradiation of the spin coated and subsequently drop casted MMA/ $\mathrm{Fe}_{2} \mathrm{O}_{3}$ NPs solution through a photomask of two parallel lines in the mm range.

During the photopolymerization, a homogeneous magnetic field produced by two permanent magnets was applied to the samples, at saturated chloroform atmosphere as shown in Figure 5. All samples prepared with or without the application of the magnetic field were studied under an optical microscope. Figure 6 presents samples with $10 \mathrm{wt}$ \% concentration of NPs. The analysis reveals that in the samples created without the application of the magnetic field (Figures 6a and 6b), the NPs form aggregates randomly distributed in the film. The application of a magnetic field produced by two magnets leads 
to NPs aligned along the magnetic field lines, forming parallel NWs (Figure $6 \mathrm{c}$ and $6 \mathrm{~d}$ ). By these two figures is demonstrated that the formation of magnetic NWs when the samples are placed under the magnetic field occurs both before and after the photopolymerization procedure, with the latter leaving unaffected the geometry of the wires. In particular, Figure $6 \mathrm{~d}$ shows that the area of the sample that was covered by the mask (bottom part of the picture) is not polymerized and thus, after washing with methanol, the composite is removed and no aligned structures are left onto the substrate.

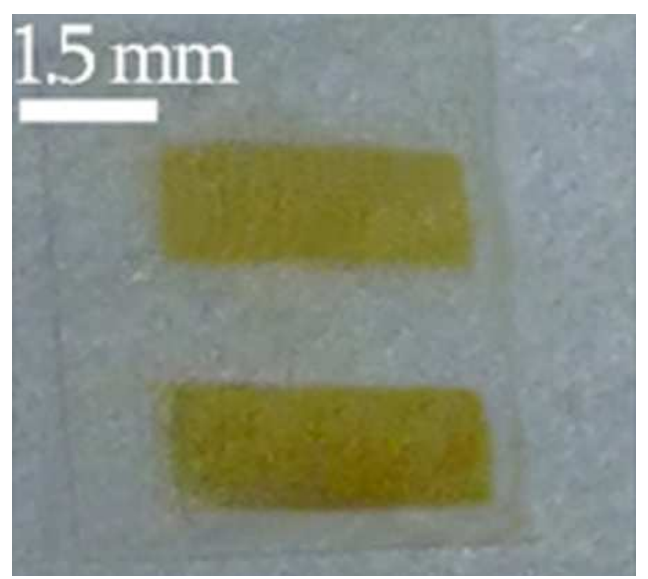

Fig. 4. Photolithographically created lines of mm-dimensions of PMMA/ $\gamma-\mathrm{Fe}_{2} \mathrm{O}_{3} \mathrm{NPs}$ nanocomposites.

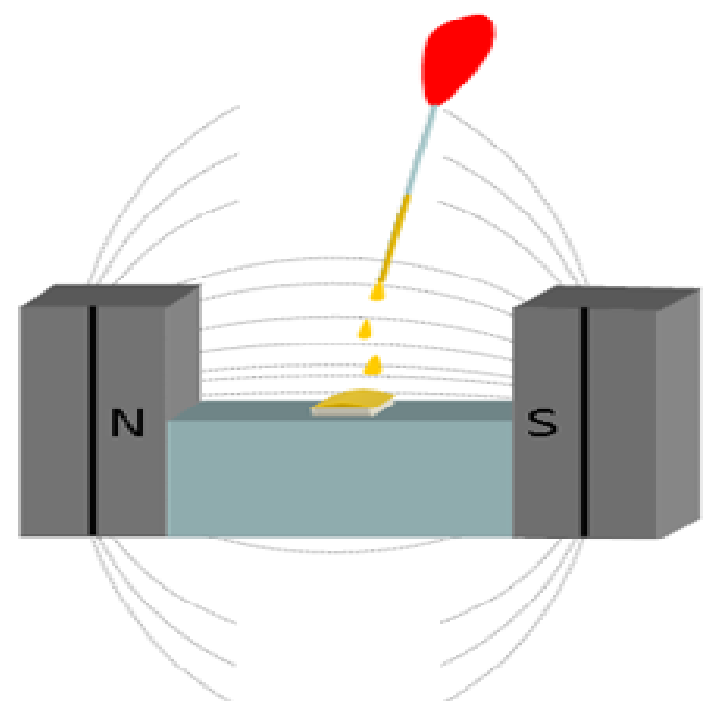

Fig. 5. Schematization of the experimental set-up where a homogeneous magnetic field is applied parallel to the samples. 

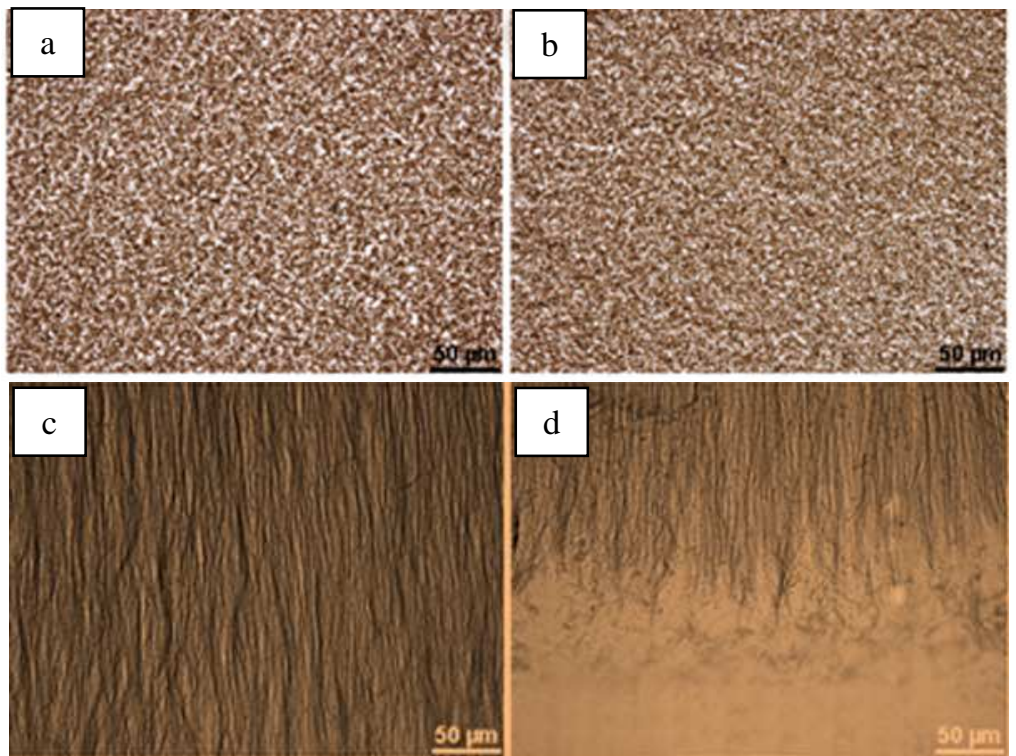

d

solm

301 in

Fig. 6. Optical microscopy images of PMMA/ $\mathrm{Fe}_{2} \mathrm{O}_{3}$ films formed without the application of a magnetic field (a) before and (b) after the photopolymerization, and with the application of a magnetic field (c) before and (d) after the photopolymerization and washing. In the panel (d) is demonstrated the edge of the photopolymerized film after the washing.

A detailed topographic study of the photolithographically produced patterns with or without the application of the magnetic field was conducted using AFM (Figures 7a-7d). Figures $7 \mathrm{a}$ and $7 \mathrm{~b}$ show the topography of samples produced in the absence of a magnetic field. The nanofillers of these samples do not show any particular alignment, as expected, but rather organize themselves in order to form aggregates of different sizes distributed all over the surface, in agreement with the results of the optical microscopy examination. On the contrary, the AFM images of the samples realized under the magnetic field produced by two magnets show the presence of parallel structures aligned along the direction of the external magnetic field (Figures 7c and 7d). In particular, parallel lines with thickness of $\sim 1$ $\mu \mathrm{m}$ and length of tens of microns clearly appear both in the 2D and in the 3D topography images. The images also demonstrate the presence of bigger aggregated structures with width around $5 \mu \mathrm{m}$, which can be attributed to aligned NWs that in some areas of the sample get very closely packed, due to the high NPs concentration. It is very likely that the NWs formation inside the photopatterned polymer are facilitated by the initial organization of the NPs into bigger clusters, as demonstrated already in Figures 7a and 7b. These clusters exhibit higher magnetic moments than the single $\mathrm{Fe}_{2} \mathrm{O}_{3} \mathrm{NPs}$, resulting in an increased response to the external magnetic field that leads eventually to chain formation (Lalatonne et al 2004).

The formation of magnetic NWs inside and on the surface of polymeric patterned structures opens up the possibility of various applications of these systems, related to the oriented growth and patterning of molecules bound on the NWs, and to the effect of this binding on the magnetic properties of the NWs. In particular, specially designed structures can be created where various biological molecules such as DNA, proteins, or cells can be bound on 
the NWs. Such structures can be extremely useful in biological applications for the formation of biological sensors, and can be also incorporated in molecular recognition devices

a

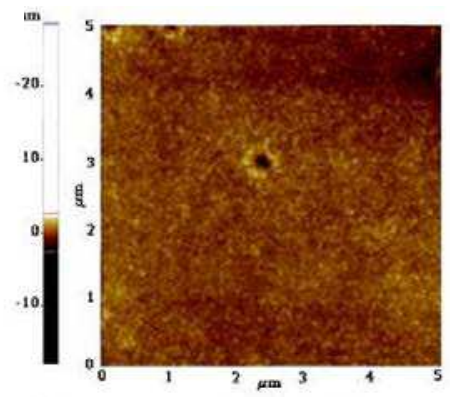

$\mathrm{c}$

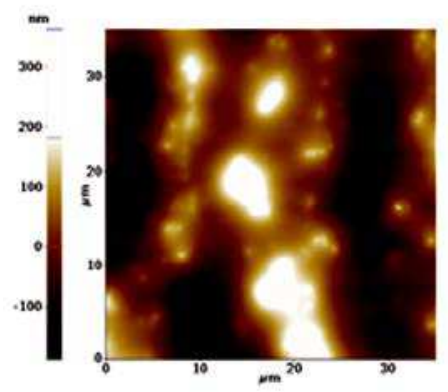

$\mathrm{b}$

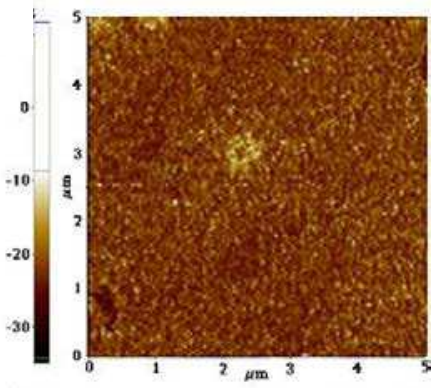

$\mathrm{d}$

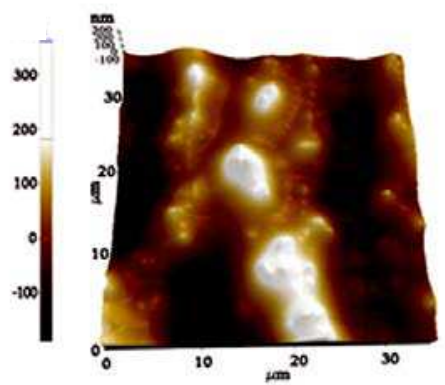

Fig. 7. AFM images of $\mathrm{PMMA} / \mathrm{Fe}_{2} \mathrm{O}_{3}$ films realized with or without a magnetic field. The images show the topography (a) and the phase (b) of a sample realized in the absence of a magnetic field, and the 2D (c) and 3D (d) topography images of a sample realized under the magnetic field of two magnets. In particular, the 2D and 3D topography images of sample areas with parallel lines show the existence of aligned structures on the surface of the sample.

\subsubsection{Photopolymerized patterns of $\mathrm{SU}-8 / \mathrm{Fe}_{2} \mathrm{O}_{3}$}

SU-8 is a commercial biocompatible epoxy-based negative photoresist that is suitable for the microfabrication of high aspect-ratio $(>20)$ structures. When exposed to UV light, its molecular chains crosslink causing the polymerization of the material. Here the SU-8 3050 (Microchem) was used for the fabrication of the SU-8 pillars. $\mathrm{Fe}_{2} \mathrm{O}_{3}$ NPs of diameter $20 \mathrm{~nm}$ in choloroform solution were prepared, by modifying the wet-chemical synthetic approach previously reported by Sun et al 2004. Size control was achieved by varying the concentration of the precursor and the surfactant-to-precursor molar ratio.

For the fabrication of SU-8 magnetic pillars the following steps were performed: The existing cyclopentanone solvent was evaporated from the SU-8 3050 resin. Subsequently, SU-8 was dissolved in chloroform (1:5 wt.) by sonication for $10 \mathrm{~min}$ and then stirring. Then, the $\mathrm{Fe}_{2} \mathrm{O}_{3}$ NPs (2 wt. \%) were slowly added and mixed with the SU-8 solution under sonication. After obtaining a homogeneous solution, the solvent was slowly evaporated under nitrogen flow, until it was obtained a nanocomposite solution viscous enough to form 
a thick coating. The solution was then spin-coated on a silicon wafer and subsequently left under a magnetic field $(400 \mathrm{mT})$ with a vertical direction with respect to the substrate, resulting in the formation of wire like magnetic structures. These magnetic wires induce magnetic anisotropy so for specific magnetic field orientations the magnetic response is higher (Fragouli \& Buonsanti et al 2010). After, the sample was irradiated with a UV lamp mask aligner for $70 \mathrm{sec}$ with energy of $25 \mathrm{~mW}$. Masks of square shaped pillar patterns were used, with $42 \mu \mathrm{m}$ side and different interpillar distances varying from 14 to $77 \mu \mathrm{m}$. The postbake was for $1 \mathrm{~min}$ at $65^{\circ} \mathrm{C}$ and for $4 \mathrm{~min}$ at $95^{\circ} \mathrm{C}$. Finally, the samples were developed with SU-8 developer (15min) and rinsed with isopropanol with subsequent drying under nitrogen flow. The fabricated nanocomposite pillars formed in this way, had a square side of $42 \mu \mathrm{m}$ and $40 \mu \mathrm{m}$ high as shown in the image recorded with Scanning Electron Microscopy (SEM) (Figure 8).

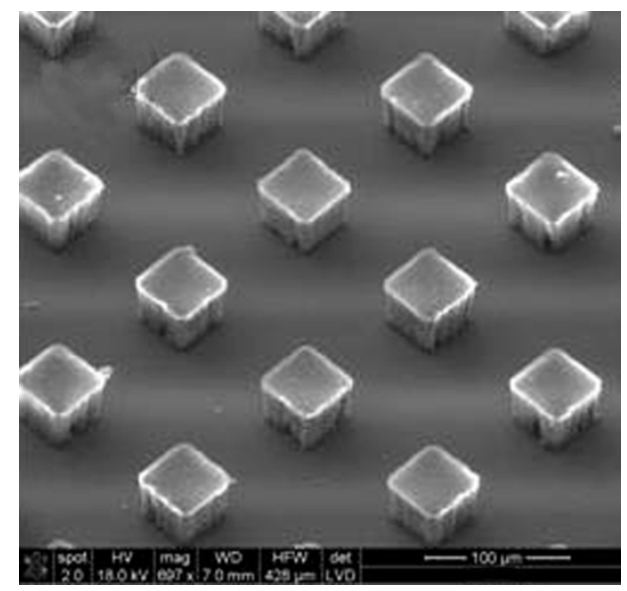

Fig. 8. SEM image of the SU-8/iron oxide nanocomposite pillar structures.

The AFM image of figure 9 demonstrates a part of the surface of a nanocomposite pillar in which the NPs are aligned vertically to the substrate. The nanoroughness shown is due to the protruding edges of the formed NWs, demonstrating that the diameters of the NWs are around $100 \mathrm{~nm}$.

The magnetic alignment of the iron oxide NPs inside the SU-8 matrix creates a magnetic anisotropy that enhances the possibility for the pillar structures to respond to an external magnetic field. The responsivity of the magnetic pillars to an external magnetic field was checked using water drops placed onto the pillars. In particular, the pillars were inclined in order to observe a difference between the right and the left part of the drops and a static magnet of maximum field strength $500 \mathrm{mT}$, was moved towards the sample with a direction parallel to it. The test was performed onto magnetic pillars with interpillar distance $14 \mu \mathrm{m}$. The water contact angle on these pillars is about $130^{\circ}$, while the values of the right and the left contact angle after the tilting of the sample are shown in table 1 . After few minutes it was observed a change in the shape of the drop when the magnet was moving towards the drop, while it was recovering when the magnet was far from the substrate. This reversible difference in the shape of the drop indicates the tendency of the drop to move, which is connected with the reversible movement of the magnetic pillars responding to the external magnetic field. 


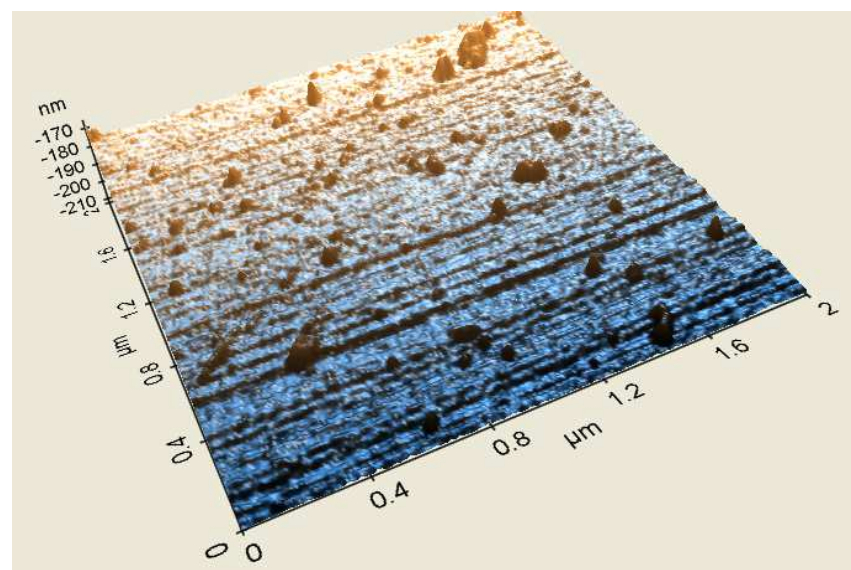

Fig. 9. AFM topography of the nanocomposite SU-8 mixed with iron oxide NPs, vertically aligned under the application of an external magnetic field.

\begin{tabular}{|c|c|c|}
\hline Right Part $\left(^{\circ}\right)$ & Left Part $\left(^{\circ}\right)$ & Drop Images \\
\hline 127 & 130 & \\
\hline 122 & 135 & \\
\hline
\end{tabular}

Table 1. Contact angle values of the left and right part of the water drop when the magnet is away from the substrate (top raw) and when the magnet in coming closer (down raw). At the right column are demonstrated the two examined frames.

\section{Lithography using light sensitive precursors of nanofillers}

In situ synthesis of NPs into their matrices is a very powerful lithographic technique because the properties of the nanocomposites can be controlled and tailored locally in a unique way. In this section we will present the laser-induced formation of NPs directly into the polymer matrices following two main strategies. The first one is based on the use of chloroauric acid salt, which is a gold $(\mathrm{Au})$ precursor, introduced in transparent polymer films. Herein, chitosan (CTO) is used as a matrix, which is a very promising polymer due to its biocompatibility. In CTO polymer, Au NPs can be generated by UV irradiation (Miyama \& Yonezawa 2004). Using photomasks and UV laser beam we obtain the creation of gold NPs in precise areas of the polymeric film, turning the insulating polymer into electron conducting material. This process allows us to localize and design accurately surface patterns and moreover to tune the metallic particle size in the range of nanoscale by varying the laser irradiation time and energy. 
Another strategy that we follow for the in situ creation of nanofillers into the polymer matrix is the UV laser irradiation of polymer films containing cadmium thiolate precursors. This method results in the spatially selective formation of cadmium sulphide (CdS) crystalline NPs in the host matrix, through a macroscopically non-destructive procedure for the matrix. Using a pulse by pulse approach, we accomplished the formation of NPs with gradually increasing dimensions, and consequently the progressive change of the emission characteristics of the formed nanocomposites. The optimized combination of irradiation wavelength with polymer matrix gives patterned nanocomposite materials incorporating nanocrystals of high quality, ready to be used in various optical applications.

\subsection{Au precursor-based nanocomposite patterns}

The use of polymeric nanocomposite materials is expanding to a huge range of applications since they combine the flexibility, easy processability and low cost of the polymers with the unique properties of the nanofillers. On the other hand the intrinsic insulating characteristic of the polymers limit the possibilities of using polymeric-based systems in devices where electronic conductivity is desired, like sensors, miniaturized electronic chips, etc. In order to overcome this limitation, the use of metallic NPs that exhibit very high electronic conductivity as nanofillers is proved to be a successive strategy (Gelves 2006, 2011, Huang et al 2009).

Our strategy is based on the use of the $\mathrm{Au}$ precursor, chloroauric acid salt $\left(\mathrm{HAuCl}_{4}\right)$, introduced in a transparent polymer film by immersion, and the generation of $\mathrm{Au}$ particles in specific areas by means of laser irradiation. The lithographically produced nanocomposite areas have tailored properties, dependent on the density and size of the produced Au NPs. The possibility to produce Au-polymeric nanocomposite materials with enhanced electrical properties, in combination with the spatial control of the specific property by introducing in situ the nanofillers in the desired areas increases enormously the potentiality of such systems in a wide variety of applications.

\subsubsection{Spatially controlled in situ formation of Au NPs in chitosan}

Chitosan (CTO) is a natural biodegradable and biocompatible polysaccharide polymer derived from chitin, a linear chain of acetylglucosamine groups, extracted from crustaceans shells and the cell walls of many fungi. CTO is fiberlike and is obtained by the deacetylation process of the natural chitin, a process that gives rise to amine groups which can be used for further functionalization (Yi et al 2005, Luther et al 2005, Su et al 2005, Zhou et al 2006, Zangmeister et al 2006). CTO is becoming widely used due to its potential polysaccharide resource and properties as non-toxicity, excellent processability, adsorption properties, hydrogel behavior, electrospinning, etc (Guibal 2005, Nirmala et al 2011). Its chemical structure is illustrated in figure 10.

CTO has a hydrogel nature resulting in the tendency to absorb ambient moisture or liquids. In this work, the process was optimized and used to introduce gold precursor in CTO polymer thin films. By controlling the immersion time of the polymer film in gold precursor solution, the absorption of gold precursors is highly controlled. The CTO used in this work was purchased from Sigma Aldrich with a degree of deacetylation about $80 \%$. Various concentrations of CTO polymer solutions $(0.5 \%, 1 \%$ and $2 \% \mathrm{wt}$.) are prepared in acetic acid. CTO polymeric films on glass substrates are obtained by drop-casting or spin-coating. The use of high CTO polymer concentration allows the formation of CTO hydrogel films able to absorb gold precursor crystals behaving as a "gold precursor reservoir". The gold precursor 
used is a chloroauric acid salt $\left(\mathrm{Mw}\left(\mathrm{HAuCl}_{4}\right)=339.5 \mathrm{~g} / \mathrm{mol}\right)$ and is dissolved in distilled water by providing two solutions $(0.01 \mathrm{M}$ and $0.02 \mathrm{M})$. Irradiation of the salt embedded in CTO with UV light induces photoreduction of metallic ions $\left(\mathrm{AuCl}_{4}^{-}\right)$into metal atoms (Duff et al 1993), clusters, aggregated metal clusters and eventually gold NPs, as described in equation 1 . The Au NPs were obtained by irradiating the samples with the third harmonic of a pulsed Nd:YAG laser $(\lambda=355 \mathrm{~nm}$, pulse duration $=4-6 \mathrm{~ns}$, repetition rate $=10 \mathrm{~Hz}$, QuantaRay GCR 190, Spectra Physics) with fluence in the range of 0.5 to $5.0 \mathrm{~J} \cdot \mathrm{cm}^{-2}$ through photomasks. The results of the lithographic production of Au NPs at adjacent areas of a representative sample irradiated with increasing irradiation times is shown in Figure 11.

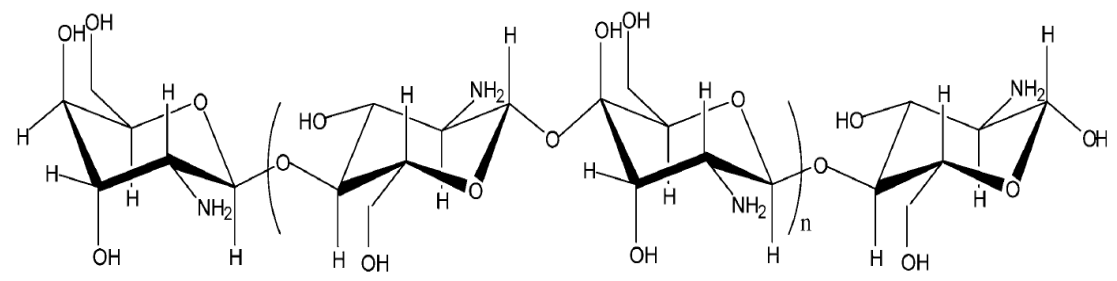

Fig. 10. Chemical structure of chitosan.

$$
\begin{gathered}
\mathrm{RNH}_{3}+\mathrm{AuCl}_{4}-\rightarrow \mathrm{Au}^{0}+\mathrm{RNH}_{3}+\mathrm{Cl}^{-}+3 \mathrm{Cl} \\
\mathrm{Au}^{0} \rightarrow \mathrm{Au}_{\mathrm{n}} \text { (cluster) } \rightarrow \mathrm{Au}_{\mathrm{p}} \text { (particles) }
\end{gathered}
$$

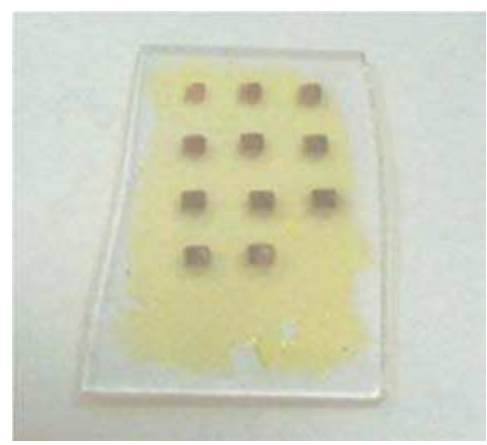

Fig. 11. Lithographic production of Au NPs at adjacent areas (dark spots) of a CTO film incorporating Au precursor, irradiated with increasing times.

For the fluence range used in this work the irradiation time needed for the creation of the NPs is very short, in the range of few seconds, and after 2-3 minutes of irradiation the $\mathrm{Au} / \mathrm{CTO}$ films appear destroyed. The generation of Au NPs at the surface of the CTO-Au polymeric film in function of the irradiation time is illustrated in the AFM images of Figure 12 , for a laser fluence of $1 \mathrm{~J} \mathrm{~cm}^{-2}$. In particular, Fig. 12a illustrates a non-irradiated area with a very smooth surface. Fig. $12 \mathrm{~b}$ demonstrates an area irradiated for $30 \mathrm{sec}$. At this stage, the photolysis reaction results in the formation of few Au NPs with low density and sub-micron size. In Fig. 12c is demonstrated the surface of an area after its irradiation for $75 \mathrm{sec}$. In this figure the Au NPs appear much denser and a clear reduction of their size is also 
demonstrated. The size of the smallest Au NPs that appear onto the surface of the sample is around $20 \mathrm{~nm}$. Under these experimental conditions, the distribution of Au NPs becomes almost homogeneous after $90 \mathrm{sec}$ and they form a sort of continuous film on the surface of the CTO film. It can also be noted that the form of the NPs seems to change from undefined geometrical structures to spherical shapes after prolonged irradiation.

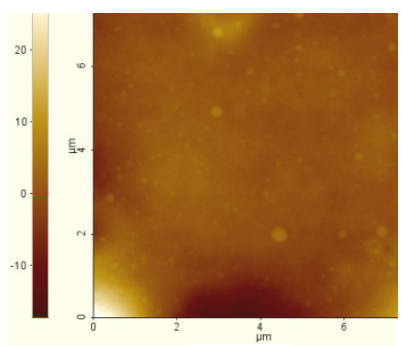

a

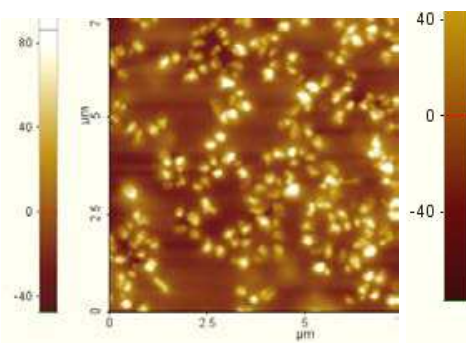

b

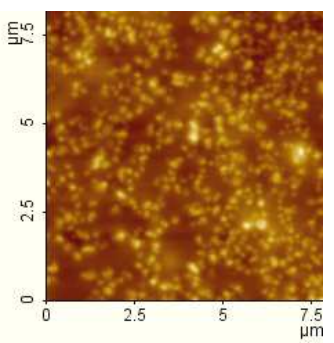

$\mathrm{c}$

Fig. 12. Evolution of the formation of the Au NPs onto the CTO surface upon increasing irradiation time: (a) non-irradiated area, (b) area irradiated for $30 \mathrm{sec}$, (c) area irradiated for $75 \mathrm{sec}$. The density of the NPs increases and their size decreases with the irradiation time.

In the literature (Miyama \& Yonezawa 2004) is mentioned that the growth of Au NPs occurs by aggregation of the photolytically formed $\mathrm{Au}$ atoms and clusters (equation 1). Nevertheless, the aggregation mechanism is not confirmed by the AFM images presented in figure 12, where is demonstrated that increasing irradiation time causes the decrease and not the increase of the size of the formed particles. The mechanism occurring in our case seems to be closer to the one reported on the formation of metal NPs by laser ablation in water solutions, where the reduced size of the NPs with increasing irradiation time is explained by their fragmentation due to self-absorption of laser pulses (Mafune' et al 2000, Shukla \& Seal 1999, Videla et al 2010, Kadossov \& Burghaus 2010, Kabashin \& Meunier 2003). Indeed, the Scanning Electron Microscopy (SEM) images obtained on the same sample irradiated at two different areas for very few seconds $(\approx 5)$ and $30 \mathrm{sec}$, respectively, using fluence of $1 \mathrm{~J} \mathrm{~cm}^{-2}$, demonstrate that the first particles that appear onto the CTO surface are quite big (in the micrometer scale) and then they fragment into smaller ones (Figure 13). A closer look into the NPs clearly demonstrates that some of them are already fragmented into smaller pieces. Due to the irradiation conditions used in our experiments the aggregation of $\mathrm{Au}$ atoms and clusters into small particles seems to occur already in the very first seconds of the procedure and then the fragmentation mechanism becomes predominant. It is also interesting to mention that the fragmentation mechanism as described in literature is linked with an increase of local temperature due to the absorption of the laser photons by the Au NPs, which may increase the mobility of the latter towards the surface of the CTO polymeric films.

Finally, in figure 14 is demonstrated the intensity of the electronic current that is conducted through a CTO/Au NPs sample as a function of the laser irradiation time, for a laser fluence of $\sim 5 \mathrm{~J} \cdot \mathrm{cm}^{-2}$. It is clear that the density increase of the formed Au NPs and the interconnection between them, previously demonstrated in figures 12 and 13, has an effect on the electrons mobility into the samples. Indeed, the current passing through the samples increases almost linearly with the laser irradiation time. The enhancement of the electrical 
conductivity in specific areas of nanocomposites by laser induced lithography, can be used for a wide range of applications such as implantable gas sensors, liquid sensors for robotics and nanocircuits.

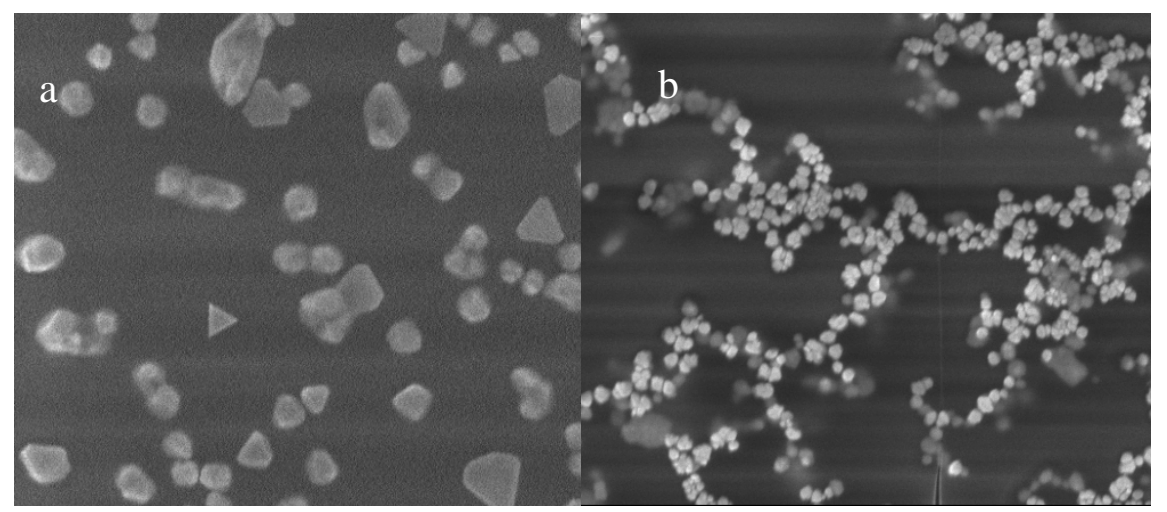

Fig. 13. SEM images showing the fragmentation of the Au NPs with increasing irradiation time: (a) area irradiated for $5 \mathrm{sec}$, (b) area irradiated for $30 \mathrm{sec}$. The density of the NPs increases and their size decreases with the irradiation time.

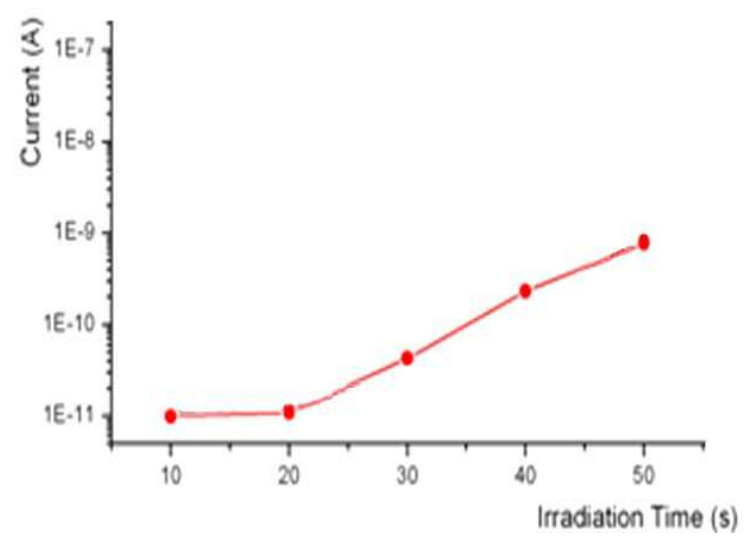

Fig. 14. Evolution of the current intensity in function of the irradiation time for laser fluence $\sim 5 \mathrm{~J} \cdot \mathrm{cm}^{-2}$.

\subsection{CdS precursor-based nanocomposite patterns}

Semiconductor nanocrystals (NCs) embedded into polymeric matrices can be exploited in several technological applications, taking advantage of the unique photophysical characteristics of the former due to the quantum confinement effect. In particular, the sizedependent optical properties of the NCs, such as, high emission quantum yields, narrow emission bands, and tunable emission/absorption spectra, have been the topic of many recent research works (Xia et al 2008, Medintz et al, 2005, Bruchez et al 1998, Michalet et al 2005). On the top, the careful selection of the polymer matrices can lead to highly processable nanocomposite materials with increased stability. 
For different applications, the lithographically patterned formation of well-dispersed NCs into polymers is highly requested, since it provides spatially selective tailoring of specific properties of the nanocomposites. Indeed, on one hand a good dispersion of the NCs optimize their quantum size effect, meaning the control of their emission properties. On the other hand, the localization of the NCs in specific sites of the polymer provides the possibility of the direct incorporation of the nanocomposites in various advanced technological devices, such as sensors, biological chips, photoemission devices, etc. In this respect our lithography approach involves the localized in-situ formation of NCs inside polymer matrices by UV laser irradiation of polymer-precursor films. We focus our study on the in situ localized formation of NCs of one very promising II-VI semiconductor, the CdS, by the use of pulsed UV laser irradiation of a polymer film incorporating the photosensitive metal sulphide precursor.

\subsubsection{Spatially controlled in situ formation of CdS NCs in polymers}

Cadmium bis-dodecanthiolate $\mathrm{Cd}\left(\mathrm{SC}_{12} \mathrm{H}_{25}\right)_{2},(\mathrm{C} 12)$, is a photosensitive metal precursor that was mixed with the polymer poly-methylmethacrylate (PMMA) or TOPAS®, a thermoplastic cyclo-olefin copolymer consisting of ethylene and norbonene units, transparent in the visible, in order to produce the CdS NCs after laser irradiation. In particular, $20 \mathrm{wt} . \%$ of the metal thiolate precursors was mixed with $80 \mathrm{wt}$. \% of polymer, and then diluted in toluene. The solutions, after being sonicated for $30 \mathrm{~min}$, were cast in Petri capsules. The polymer-precursor films formed after the evaporation of toluene had thickness $\sim 200 \mu \mathrm{m}$.

For the in situ formation of the NCs in the polymer matrix, the films were irradiated through photomasks of different shapes with pulses of Nd:YAG laser (Quanta-Ray PRO-290-30, Spectra Physics) operating at the fourth harmonic, (wavelength $266 \mathrm{~nm}$, pulse duration $8 \mathrm{~ns}$, and repetition rate $2 \mathrm{~Hz}$ ). The wavelength $266 \mathrm{~nm}$ was chosen since the metal precursor exhibits at it enhanced absorption, as demonstrate in figure 15. Both TOPAS and PMMA polymers have intriguing physical properties for a number of applications, taking advantage at the same time of the in situ photoinduced CdS nanocomposite micropatterns with accurate control of the NCs size upon UV irradiation.
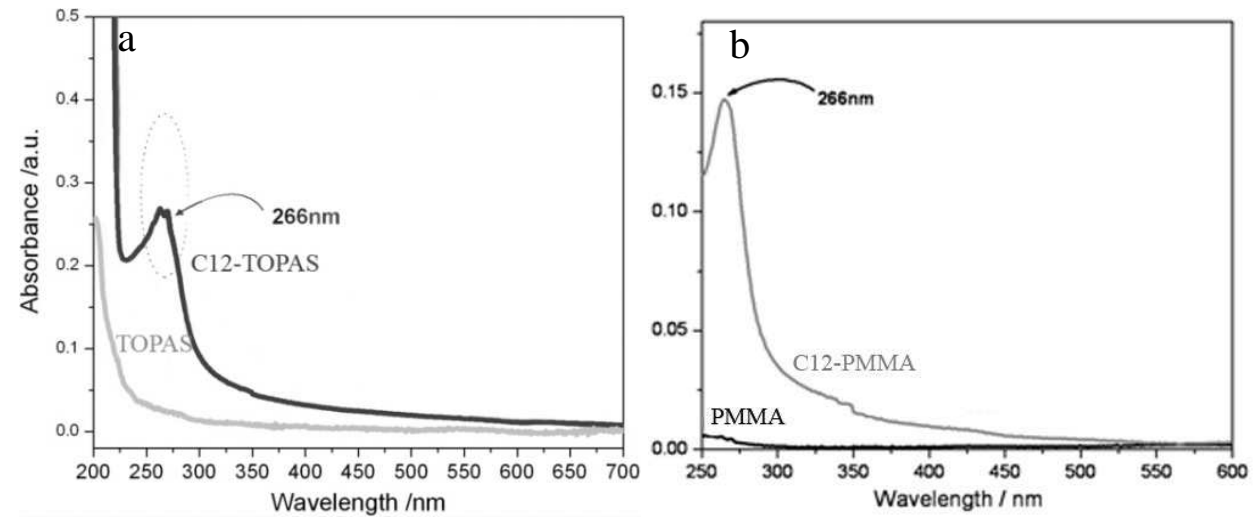

Fig. 15. Normalized absorption spectra of the precursor C12 mixed with the polymers (a), and of the pure TOPAS and PMMA (b). 
Upon laser irradiation through photomasks the CdS NCs are localized exclusively in the irradiated area, making possible the lithographic patterning of the samples. A characteristic micro pattern of 3 lines is illustrated in figure 16. For the specific pattern the lithographic technique that we used was not involving photomasks but it was done by focusing the laser beam on the C12-TOPAS sample, which was fixed onto a motorized stage moving at constant velocity. The spot size of the beam was $\sim 0.2 \times 0.1 \mathrm{~mm}^{2}$, and the speed of the motor about $0.2 \mathrm{~mm} \cdot \mathrm{s}^{-1}$. The lines are fairly clear and their width $(240 \mu \mathrm{m})$ is constant along the irradiation path. The total number of pulses in each spot area is about 100 and is enough to form CdS NCs, as demonstrated by their emission spectra shown in figure 16. The bright areas correspond to CdS NCs in the bulk region, since the spectrum has the characteristic emission peak at $506 \mathrm{~nm}$, while the dark areas, not being irradiated, have no fluorescence emission in the studied spectral region.

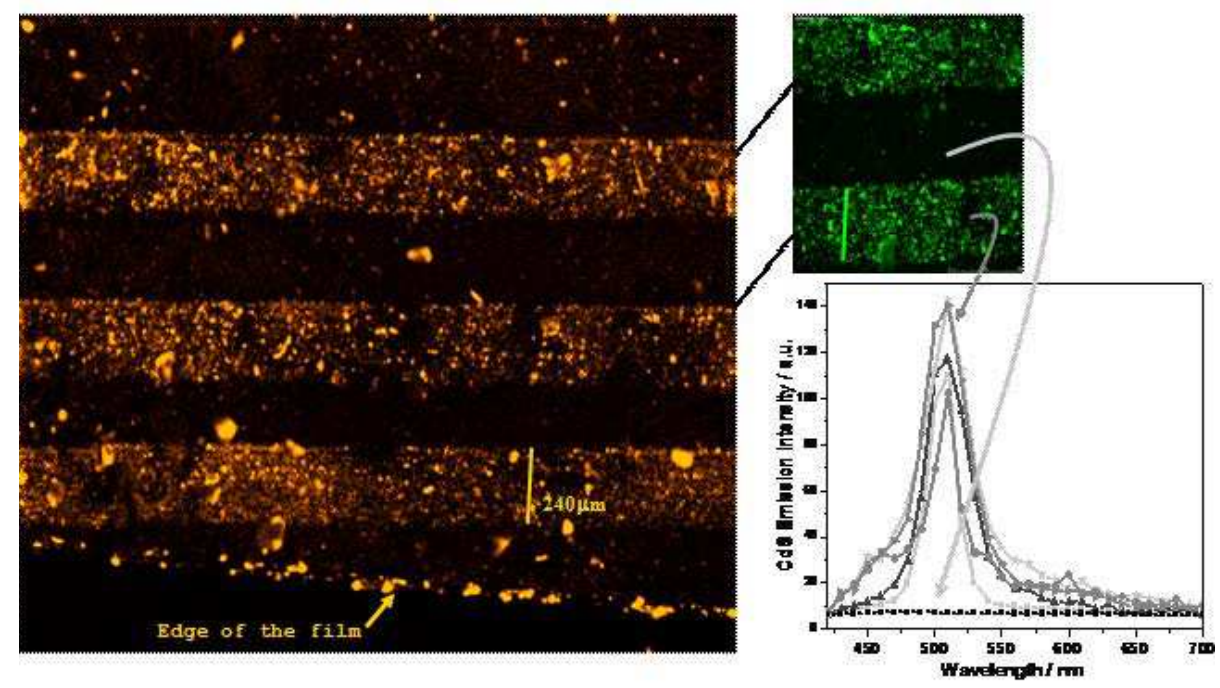

Fig. 16. Fluorescence image of a patterned sample of cadmium thiolate precursor-TOPAS polymer excited with a $405 \mathrm{~nm}$ diode laser after irradiation at $266 \mathrm{~nm}$. The narrow fluorescence spectra of the formed CdS NCs are also shown.

The formed CdS NCs following an increasing number of laser pulses are characterized by spatially resolved photoluminescence measurements using a confocal microscope. Indeed, in figure 18 are presented the fluorescence spectra from selected areas of the films irradiated with various laser pulses at a laser fluence of $25 \mathrm{~mJ} \cdot \mathrm{cm}^{-2}$. After 6 pulses the emission peak of the formed NCs is close to $\lambda=440 \mathrm{~nm}$. After successive laser pulses the emission is shifted towards higher wavelengths with the peak reaching $506 \mathrm{~nm}$ above 40 laser pulses, which coincides with the emission of the bulk CdS material. It is clearly demonstrated that the luminescence of the samples changes dramatically after the first irradiation pulses, while an increase of the incident pulses causes a red shift to the emission, which is attributed to the increasing dimensions of the CdS NCs. Therefore, the UV irradiation of metal precursorTOPAS polymer films results in the formation of CdS NCs, with dimensions extending from the quantum size effect range to the bulk, depending on the number of the incident laser 
pulses. This, in combination with the spatial control of the formation of these NCs thanks to the presented lithographic technique opens the way for the incorporation of such systems in complex multicomponent devides.

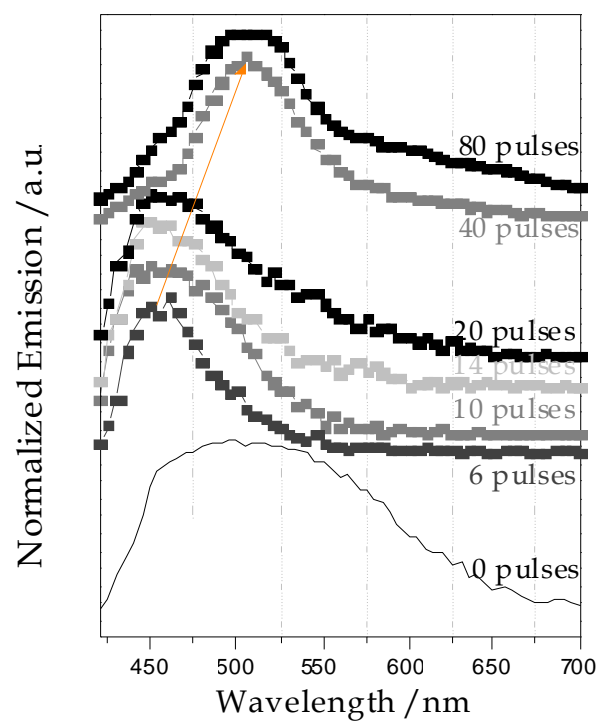

Fig. 17. The change of the fluorescence spectra of C12-TOPAS film with an increasing number of incident laser pulses.

The lithographic formation and size tuning of CdS NCs with increasing UV irradiation time of metal precursors occurs also in PMMA, in the same way as in TOPAS. However, intense deteriorations (broadening) are observed in the emission spectra of the NCs formed in PMMA compared to TOPAS upon increasing number of pulses. Figure 18 shows the fluorescence image of a C12-PMMA film irradiated with 80 laser pulses of fluence $F=20$ $\mathrm{mJ} \cdot \mathrm{cm}^{-2}$, at $\lambda=266 \mathrm{~nm}$, and the corresponding emission taken from various areas of the film using a confocal microscope. The emission spectra show the existence of few CdS NCs emitting at the bulk region (NCs diameter $>7 \mathrm{~nm}$ ) with an emission peak close to $500 \mathrm{~nm}$ and FWHM $\sim 32 \mathrm{~nm}$ (Figure 18b), while many areas exhibit a very broad emission with the peak around $550 \mathrm{~nm}$ (Figure 18b, blue line), representative of the trap states emission formed on the surface of the NCs. Indeed, the quality of the semiconductor NCs is generally studied by their emission characteristics verifying that the broader the emission spectra the higher the number of the trap states on their surfaces (Athanassiou et al 2007, Fragouli et al 2009, 2010, Wang et al 2004, Antoun et al 2007, Wu et al 2000, Khanna et al 2007). After irradiation with the same number of laser pulses but increased laser fluence $\left(F=50 \mathrm{~mJ} \cdot \mathrm{cm}^{-2}\right.$, 80 pulses) the characteristic emission of the NCs in PMMA matrix is no more evident in the irradiated area, while the trap state emission is dominant (Figure 18c). Therefore, when PMMA matrix is used the laser irradiation at $266 \mathrm{~nm}$ results in the formation of NCs with trap states on their surface, an evidence that becomes clearer as the incident fluence increases. The comparison between the emission spectra of the CdS NCs formed in the TOPAS and in the PMMA matrix shows that they are very narrow and characteristic of CdS 
in the first case while they are broad and red shifted in the second case. This finding demonstrates that the trap states on the NCs surfaces formed with laser lithography, and thus, the optical quality of the NCs strongly depends on the surrounding matrix.
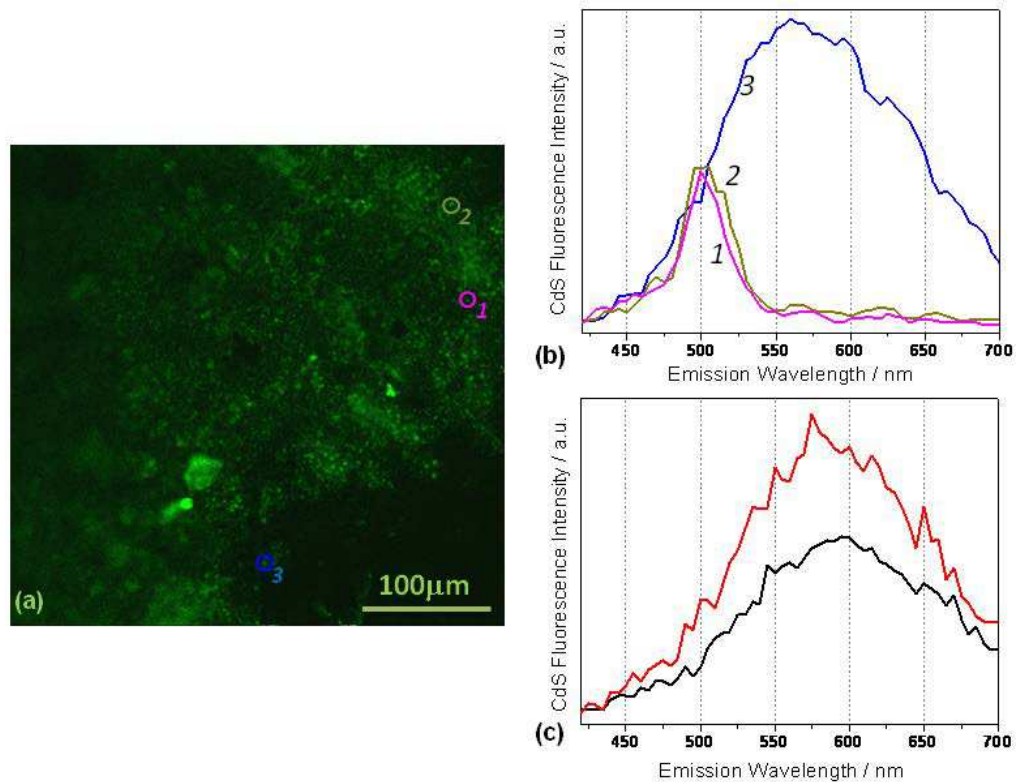

Fig. 18. (a) Confocal microscopy fluorescence image of the C12-PMMA film after irradiation at $266 \mathrm{~nm}$ with 80 incident pulses and fluence $\mathrm{F}=20 \mathrm{~mJ} \cdot \mathrm{cm}^{-2}$. (b) Emission spectra of selected areas of the image; each curve corresponds to the marked area of (a) with the same colour and number. (c) Emission spectra of selected areas of the C12-PMMA film after irradiation at $266 \mathrm{~nm}$ with 80 incident pulses and higher fluence $\mathrm{F}=50 \mathrm{~mJ} \cdot \mathrm{cm}^{-2}$.

\section{Conclusion}

In this work are demonstrated two different lithography techniques based on the use of pulsed UV laser light for the creation of well defined polymeric nanocomposite structures. The presented techniques open up new ways for nanocomposite film patterning with well dispersed and occasionally size controlled NCs. The first technique is the UV laser photopolymerization lithography, where UV laser pulses are used for the polymerization and patterning of nanocomposite solutions of preformed colloidal NPs mixed with monomers and photoinitiators. In the second lithography technique UV laser pulses induce the in situ formation of NPs in specific locations in the polymer matrices, starting from polymeric film incorporating light-sensitive precursors of NPs. Using both techniques we present patterned structures of various nanocomposite systems, such as PMMA with $\mathrm{TiO}_{2}$ NPs, PMMA and SU-8 with $\mathrm{Fe}_{2} \mathrm{O}_{3}$ NPs aligned into NWs under external magnetic field, CTO with Au NPs, TOPAS and PMMA with size tuned CdS NPs. The formed nanocomposite structures can exhibit controlled and enhanced surface, optical, electronically conducting and magnetic properties, in an easy and fast way, promising for 
the development of nanodevices used in biotechnology, optoelectronics, microfluidics and other advanced technological areas.

\section{Acknowledgment}

The authors would like to thank Dr Rafaella Buonsanti, Dr Gianvito Caputo, Dr P. D Cozzoli, Dr Anna Maria Laera, Professor Leander Tapfer who provided us with diverse colloidal nanofillers or nanocomposite samples and for the fruitful discussions and suggestion that helped in the realization of this research work.

\section{References}

Andrzejewska, E. (2001). Photopolymerization kinetics of multifunctional monomers. Progress in Polymer Science, Vol. 26, No. 4, (May 2001), pp. 605-665, ISSN 0079-6700

Antoun, T.; Brayner, R.; Alterary, S.; Fiévet, F.; Chehimi, M.; Yassar, A. (2007). Facile Synthesis of Oligothiophene-Capped CdS Nanoparticles. European Journal of Inorganic Chemistry, Vol. 2007, No. 9, (March 2007), pp. 1275-1284, ISSN 1099-0682

Athanassiou, A.; Cingolani, R.; Tsiranidou, E.; Fotakis, C.; Laera, A. M.; Piscopiello, E.; Tapfer, L. (2007). Photon-induced formation of CdS nanocrystals in selected areas of polymer matrices. Applied Physics Letters, Vol. 91, No. 15, (October 2007), 153108, ISSN 1077-3118

Athanassiou, A.; Blasi, L.; De Giorgi, M.; Caputo, G.; Fragouli, D.; Tsiranidou, E.; Laera, A. M.; Tapfer, L.; Cingolani, R. (2010). Comparison between laser-induced nucleation of ZnS and CdS nanocrystals directly into polymer matrices. Polymer Composites, Vol. 31, No. 6, (June 2010), pp. 1075-1083, ISSN 1548-0569

Athanassiou, A.; Cingolani, R.; Caputo, G.; Cortese, B.; Gigli, G.; Nobile, C.; Cozzoli, P. D. (2010). Reversible wettability of hybrid organic/inorganic surfaces of systems upon light irradiation/storage cycles. Internal Journal of Nanomanufacturing, Vol. 6, No. 1/2/3/4, pp. 312-323, ISSN 1746-9406

Azhar Uddin, M.; Tsuda, H.; Wu, S.; Sasaoka, E. (2008). Catalytic decomposition of biomass tars with iron oxide catalysts. Fuel, Vol. 87, No. 4-5, (April 2008), pp. 451-459, ISSN 0016-2361

Bangar, M. A.; Hangarter, C. M.; Yoo, B.; Rheem, Y.; Chen, W.; Mulchandani, A.; Myung, N. V. (2009). Magnetically Assembled Multisegmented Nanowires and Their Applications. Electroanalysis, Vol. 21, No. 1, (January 2009), pp. 61-67, ISSN 15214109

Bruchez, M. Jr.; Moronne, M.; Gin, P.; Weiss, S.; Alivisatos, A. P. (1998) Semiconductor Nanocrystals as Fluorescent Biological Labels. Science, Vol. 281, No. 25, (September 1998), pp. 2013-2016, ISSN 1095-9203

Buerli, T.; Pellegrino, C.; Baer, K.; Lardi-Studler, B.; Chudotvorova, I.; Fritschy, J.-M.; Medina, I.; Fuhrer, C. (2007). Efficient transfection of DNA or shRNA vectors into neurons using magnetofection. Nature Protocols, Vol. 2, No. 12, (December 2007), pp. 3090-3101, ISSN 1750-2799

Caputo, G.; Nobile, C.; Kipp, T.; Blasi, L.; Grillo, V.; Carlino, E.; Manna, L.; Cingolani, R.; Cozzoli, P. D.; Athanassiou, A. (2008). Reversible Wettability Changes in Colloidal TiO2 Nanorod Thin-Film Coatings under Selective UV Laser Irradiation. Journal of Physical Chemistry C, Vol. 112, No. 3, (January 2008), pp. 701-714, ISSN 1932-7455

Caputo, G.; Cortese, B.; Nobile, C.; Salerno, M.; Cingolani, R.; Gigli, G.; Cozzoli, P. D.; Athanassiou, A. (2009). Reversibly Light-Switchable Wettability of Hybrid 
Organic/Inorganic Surfaces With Dual Micro-/Nanoscale Roughness. Advanced Functional Materials, Vol. 19, No. 8, (April 2009), pp. 1149-1157, ISSN 1616-3028

Caputo, G.; Cingolani, R.; Cozzoli, P. D.; Athanassiou, A. (2009). Wettability conversion of colloidal $\mathrm{TiO}_{2}$ nanocrystal thin films with UV-switchable hydrophilicity. Physical Chemistry Chemical Physics, Vol. 11, No. 19, pp. 3692 - 3700, ISSN 1463-9076

Caputo, G.; Nobile, C.; Buonsanti, R.; Kipp, T.; Manna, L.; Cingolani, R.; Cozzoli, P. D.; Athanassiou, A. (2008). Determination of surface properties of various substrates using $\mathrm{TiO}_{2}$ nanorod coatings with tunable characteristics. Journal of Material Science, Vol. 43, No. 10, (May 2008), pp. 3474-3480, ISSN 1573-4803

Cornell, R. M.; Schwertmann, U. (2003). The Iron Oxides: Structure, Properties, Reactions, Occurrences and Uses, second ed. Wiley-VCH, Weinheim

Cui, X.J.; Antonietti, M.; Yu, S.H. (2006). Structural Effects of Iron Oxide Nanoparticles and Iron Ions on the Hydrothermal Carbonization of Starch and Rice Carbohydrates. Small, Vol. 2, No. 6, (June 2006), pp. 756-759, ISSN 1613-6829

Decker, C.; Keller, L.; Zahouily, K.; Benfarhi, S. (2005). Synthesis of nanocomposite polymers by UV-radiation curing. Polymer, Vol. 46, No. 17, (August 2005), pp. 6640-6648, ISSN 1521-4095

Ding, T.; Song, K.; Clays, K.; Tung, C.-H. (2009). Fabrication of 3D Photonic Crystals of Ellipsoids: Convective Self-Assembly in Magnetic Field. Advanced Materials, Vol. 21, No. 19, (May 2009), pp. 1936-1940, ISSN 1521-4095

dos Santos Coelho, F.; Ardisson, J.D.; Moura, F.C.C.; Lago, R.M.; Murad, E.; Fabris, J.D. (2008). Potential application of highly reactive $\mathrm{Fe}(0) / \mathrm{Fe}_{3} \mathrm{O}_{4}$ composites for the reduction of $\mathrm{Cr}(\mathrm{VI})$ environmental contaminants. Chemosphere, Vol. 71, No 1, (March 2008), pp. 90-96, ISSN 0045-6535

Duff, D. G.; Baiker, A.; Edwards, P. P. (1993). A new hydrosol of gold clusters. 1. Formation and particle size variation. Langmuir, Vol. 9, No. 9, (September 1993), pp. 2301-2309, ISSN 1520-5827

Fahrni, F.; Prins, M. W. J.; van Ijzendoorn, L. J. (2009). Magnetization and actuation of polymeric microstructures with magnetic nanoparticles for application in microfluidics. Journal of Magnetism and Magnetic Materials, Vol. 321, No. 12, (June 2009), pp. 1843-1850, ISSN 0304-8853

Fouassier, J. P. (1995) Photoiniatiation, Photopolymerization and Photocuring: Fundamentals and Applications, Hanser/gardner Publications Inc., Cincinnati 1995.

Fragouli, D.; Resta, V.; Pompa, P. P.; Laera, A. M.; Caputo, G.; Tapfer, L.; Cingolani, R.; Athanassiou, A. (2009). Patterned Structures of In-Situ Size Controlled CdS Nanocrystals in a Polymer Matrix Under UV Irradiation. Nanotechnology, Vol. 20, No. 15, (April 2009), 155302, ISSN 1361-6528

Fragouli, D.; Laera, A. M.; Pompa, P. P.; Caputo, G.; Resta, V.; Allione, M.; Tapfer, L.; Cingolani, R.; Athanassiou, A. (2009). Localized formation and size tuning of CdS nanocrystals upon irradiation of metal precursors embedded in polymer matrices. Microelectronic Engineering, Vol. 86, No. 4-5, (April-June 2009), pp. 816-819, ISSN 0167-9317.

Fragouli D.; Laera, A. M.; Caputo, G.; Resta, V.; Pompa, P. P.; Tapfer, L.; Cingolani, R., Athanassiou, A. (2010). The Effect of Polymer Matrices in the In-Situ CdS Formation Under UV Irradiation of Precursor-Polymer Films. Journal of Nanoscience and Nanotechnology, Vol. 10, No. 2, (February 2010), pp. 1267-1272, ISSN 1361-6528

Fragouli D., Buonsanti, R.; Bertoni, G.; Sangregorio, C.; Innocenti, C.; Falqui, A.; Gatteschi, D.; Cozzoli, P. D.; Athanassiou, A.; Cingolani, R. (2010). Dynamical Formation of 
Spatially Localized Arrays of Aligned Nanowires in Plastic Films with Magnetic Anisotropy. ACS NANO, Vol. 4, No. 4, (April 2010), pp. 1873-1878, ISSN 1936-086X

Fragouli D., P.P. Pompa, M. Kalyva, G. Caputo, L. Tapfer, R. Cingolani, A. Athanassiou, (2010). The Effect of Irradiation Wavelength on the Quality of CdS Nanocrystals Formed Directly into PMMA Matrix. Journal of Physical Chemistry C, Vol. 114, No. 33, (August 2010), pp. 13985-13990, ISSN 1932-7455

Fragouli, D.; Torre, B.; Bertoni, G.; Buonsanti, R.; Cingolani, R.; Athanassiou, A. (2010). Formation and microscopic investigation of iron oxide aligned NWs into polymeric nanocomposite films. Microscopy Research and Technique, Vol. 73, No. 10, (October 2010), pp. 952-958, ISSN 1097-0029

Fujishima, A.; Rao Tata, N.; Tryk, D. A. (2000). $\mathrm{TiO}_{2}$ photocatalysts and diamond electrodes. Electrochimica Acta, Vol. 45, No. 28, (October 2000), pp. 4683-4690, ISSN 0013-4686

Gelves G. A.; Lin B.; Sundararaj U.; Haber J. A. (2006). Low Electrical Percolation Threshold of Silver and Copper Nanowires in Polystyrene Composites. Advanced Functional Materials, Vol. 16, No. 18, (December 2006), pp. 2423-2430, ISSN 1616-3028

Gelves, G. A.; Al-Saleh M. H.; Sundararaj U. (2011). Highly electrically conductive and high performance EMI shielding nanowire/polymer nanocomposites by miscible mixing and precipitation. Journal of Material Chemistry, Vol. 21, No. 3, pp. 829-836, ISSN 1573-4803

Ghosh, A.; Fischer, P. (2009). Controlled Propulsion of Artificial Magnetic Nanostructured Propellers. Nano Letters, Vol. 9, No. 6, (June 2009), pp. 2243-2245, ISSN 1530-6992

Guibal, E. (2005). Heterogeneous catalysis on chitosan-based materials: a review. Progress Polymer Science, Vol. 30, No. 1, (January 2005), pp. 71-109, ISSN 0079-6700

Gupta, A. K.; Gupta, M. (2005). Synthesis and surface engineering of iron oxide nanoparticles for biomedical applications. Biomaterials, Vol. 26, No. 18, (June 2005), 3995-4021, ISSN 0142-9612

Huang, X.; Kim, C; Jiang, P; Yin, Y; Li, Z. (2009). Influence of aluminum nanoparticle surface treatment on the electrical properties of polyethylene composites. Journal of Applied Physics, Vol. 105, No. 1, (Janury 2009), 014105, ISSN 1089-7550

Huo, J.; Wang, L.; Yu, H. (2009). Polymeric nanocomposites for electromagnetic wave absorption. Journal of Material Science, Vol. 44, No. 15, (August 2009), pp. 3917-3927, ISSN 1573-4803

Jestin, J.; Cousin, F.; Dubois, I.; Ménager, C.; Schweins, R.; Oberdisse, J.; Boué, F. (2008). Anisotropic Reinforcement of Nanocomposites Tuned by Magnetic Orientation of the Filler Network. Advanced Materials, Vol. 20, No. 13, (July 2008), pp. 2533-2540, ISSN 1521-4095

Kabashin A. V.; Meunier M.. (2003). Synthesis of colloidal nanoparticles during femtosecond laser ablation of gold in water. Journal of Applied Physics, Vol. 94, No. 12, (December 2003), 7941, ISSN 1089-7550

Kado, T. (2008). Structural and magnetic properties of magnetite-containing epitaxial iron oxide films grown on $\mathrm{MgO}(001)$ substrates. Journal of Applied Physics, Vol. 103, No. 4 (February 2008), 043902, ISSN 1089-7550

38 Kadossov, E.; Burghaus, U. (2010). Adsorption Dynamics of CO on Silica Supported Gold Clusters: Cluster Size Effects in Molecular Beam Scattering Experiments. Catalysis Letters, Vol. 134, No. 3-4, (February 2010), pp. 228-232, ISSN 1572-879X

Kaushik, A.; Solanki, P. R.; Ansaria, A. A.; Sumanaa, G.; Ahmadb, S.; Malhotraa, B. D. (2009). Iron oxide-chitosan nanobiocomposite for urea sensor. Sensors and Actuators B, Vol. 138, No. 2, (May 2009), pp. 572-580, ISSN 0925-4005 
Kavcic, B.; Babic, D.; Osterman, N.; Podobnik, B.; Poberaj, I. (2009). Magnetically actuated microrotors with individual pumping speed and direction control. Applied Physics Letters, Vol. 95, No. 2, (July 2009), 023504, ISSN 1077-3118

Khanna P. K.; Singh, N. (2007). Light Emitting CdS Quantum Dots in PMMA: Synthesis and Optical Studies. Journal of Luminescence, Vol. 127, No. 2, (December 2007), pp. 474482, ISSN 0022-2313

Lalatonne, Y.; Richardi, J.; Pileni, M. P. (2004). Van der Waals versus dipolar forces controlling mesoscopic organizations of magnetic nanocrystals. Nature Materials, Vol. 3, No. 2, (February 2004), pp. 121-125, ISSN 1476-4660

Lee, B.-H.; Choi, J.-H.; Kim, H.-J. (2006). Coating performance and characteristics for UVcurable aliphatic urethane acrylate coatings containing norrish type I photoinitiators. Journal of Coatings Technology and Research, Vol. 3, No. 3, (July 2006), pp. 221-229, ISSN 1935-3804

Long, Y. (2005). Electrical and magnetic properties of polyaniline $/ \mathrm{Fe}_{3} \mathrm{O}_{4}$ nanostructures. Physica B: Condensed Matter, Vol. 370, No. 1-4, (December 2005), 121-130, ISSN 09214526

Luther, M.; Parry, J.; Moore, J.; Meng, J.; Zhang, Y.; Cheng, Z.; Yu, L. (2007). Inhibitory effect of Chardonnay and black raspberry seed extracts on lipid oxidation in fish oil and their radical scavenging and antimicrobial properties. Food Chemistry, Vol. 104, No. 3, pp. 1065-1073, ISSN 0308-8146

Mafuné, F.; Kohno, J.; Takeda, Y.; Kondow, T.; Sawabe, H. (2000). Formation and Size Control of Silver Nanoparticles by Laser Ablation in Aqueous Solution. Journal of Physical Chemistry B, Vol. 104, No. 39, (October 2000), pp. 9111-9117, ISSN 1520-5207

Mair, L.; Ford, K.; Alam, M. R.; Kole, R.; Fisher, M.; Superfine, R. (2009). Size-Uniform 200 nm Particles: Fabrication and Application to Magnetofection. Journal of Biomedical Nanotechnology, Vol. 5, No. 2, (April 2009), pp. 182-191, ISSN 1550-7041

Medintz, I. L.; Tetsuouyeda, H.; Goldman, E. R.; Mattoussi, H. (2005). Quantum Dot Bioconjugates for Imaging, Labelling and Sensing. Nature Materials, Vol. 4, No. 6, (June 2005), pp. 435-446, ISSN 1476-4660

Merkel, T. C.; Freeman, B. D.; Spontak, R. J.; He, Z.; Pinnau, I.; Meakin, P.; Hill, A. J. (2002). Ultrapermeable, Reverse-Selective Nanocomposite Membranes. Science, Vol. 296, (April-June 2002), pp. 519-522, ISSN 1095-9203

Michalet, X.; Pinaud, F. F.; Bentolila, L. A.; Tsay, J. M.; Doose, S.; Li, J. J.; Sundaresan, G.; Wu, A. M.; Gambhir, S. S.; Weiss, S. (2005). Quantum Dots for Live Cells, in Vivo Imaging, and Diagnostics. Science, Vol. 307, (October-December), pp. 538-544, ISSN 1095-9203

Miyama, T.; Yonezawa, Y. (2004). Aggregation of Photolytic Gold Nanoparticles at the Surface of Chitosan Films. Langmuir, Vol. 20, No. 14, (July 2004), pp. 5918-5923, ISSN 1520-5827

Myroshnychenko V., J. Rodriguez-Fernandez, I. Pastoriza-Santos, A. M. Funston, C. Novo, P. Mulvaney, L. M. Liz-Marzan, F. J. Garcia de Abajo, (2008). Modelling the optical response of gold nanoparticles. Chemical Society Reviews, Vol. 37, No. 9, pp. 17921805, ISSN 1460-4744

Nakajima, A.; Koizumi, S.-I.; Watanabe, T.; Hashimoto, K. (2001). Effect of repeated photoillumination on the wettability conversion of titanium dioxide. Journal of Photochemistry and Photobiology A, Vol. 146, No. 1-2, (December 2001), pp. 129-132, ISSN 1010-6030 
Nakajima, A.; Koizumi, S.-I.; Watanabe, T.; Hashimoto, K. (2000). Photoinduced Amphiphilic Surface on Polycrystalline Anatase $\mathrm{TiO}_{2}$ Thin Films. Langmuir, Vol. 16, No. 17, (August 2000), pp. 7048-7050, ISSN 1520-5827

Neuberger, T. ; Schopf, B.; Hofmann, H.; Hofmann, M.; von Rechenberg, B. (2005). Superparamagnetic nanoparticles for biomedical applications: Possibilities and limitations of a new drug delivery system. Journal of Magnetism and Magnetic Materials, Vol. 293, No. 1, (May 2005), pp. 483-496, ISSN 0304-8853

Nirmala, R.; Navamathavan, R.; El-Newehy, M. H.; Kim, H. Y. (2011). Preparation and electrical characterization of polyamide-6/chitosan composite nanofibers via electrospinning. Materials Letters, Vol. 65, No. 3, (February 2011), pp. 493-496, ISSN 0167-577X

Pankhurst, Q. A.; Connolly, J.; Jones, S. K., Dobson, J. (2003). Applications of magnetic nanoparticles in biomedicine. Journal of Physics D, Vol. 36, No. 13, (July 2003), pp. R167-R181, ISSN 1361-6463

Park, J. I.; Jun, Y. W.; Choi, J. S.; Cheon, J. (2007). Highly crystalline anisotropic superstructures via magnetic field induced nanoparticle assembly. Chemical Communications, Vol. 2007, No. 47, 5001-5003, ISSN 1364-548X

Sakai, N.; Fujishima, A.; Watanabe, T.; Hashimoto, K. (2001). Enhancement of the Photoinduced Hydrophilic Conversion Rate of $\mathrm{TiO}_{2}$ Film Electrode Surfaces by Anodic Polarization. Journal of Physical Chemistry B, Vol. 105, No. 15, (April 2001), pp. 3023-3026, ISSN 1520-5207

Sakai, N.; Fujishima, A.; Watanabe, T.; Hashimoto, K. (2003). Quantitative Evaluation of the Photoinduced Hydrophilic Conversion Properties of $\mathrm{TiO}_{2}$ Thin Film Surfaces by the Reciprocal of Contact Angle. Journal of Physical Chemistry B, Vol. 107, No. 4, (January 2003), pp. 1028-1035, ISSN 1520-5207

Sakai, N.; Wang, R.; Fujishima, A.; Watanabe, T.; Hashimoto, K. (1998). Effect of Ultrasonic Treatment on Highly Hydrophilic $\mathrm{TiO}_{2}$ Surfaces. Langmuir, Vol. 14, No. 20, (September 1998), pp. 5918-5920, ISSN 1520-5827

Shukla S.; Seal, S. (1999). Cluster size effect observed for gold nanoparticles synthesized by sol-gel technique as studied by X-ray photoelectron spectroscopy. NanoStructured Materials, Vol. 11, No. 8, (November 1999), pp. 1181-1193, ISSN 0965-9773

Su, L.; Yin, J.-J.; Charles, D.; Zhou, K.; Moore, J.; Yu, L. (2005). Total phenolic contents, chelating capacities, and radical-scavenging properties of black peppercorn, nutmeg, rosehip, cinnamon and oregano leaf. Food Chemistry, Vol. 100, No. 3, pp. 990-997, ISSN 0308-8146

Sun Z.-B.; Dong X.-Z.; Chen W.-Q.; Nakanishi S.; Duan X.-M.; Kawata S. (2008). Multicolor Polymer Nanocomposites: In Situ Synthesis and Fabrication of 3D Microstructures. Advanced Materials, Vol. 20, No. 5, (March 2008), pp. 914-919, ISSN 1521-4095

Sun, S.; Zeng, H.; Robinson, D. B.; Raoux, S.; Rice, P. M.; Wang, S. X.; Li, G. (2004). Monodisperse $\mathrm{MFe}_{2} \mathrm{O}_{4}(\mathrm{M}=\mathrm{Fe}, \mathrm{Co}, \mathrm{Mn})$ Nanoparticles. Journal of American Chemical Society, Vol. 126, No. 1, (January 2004), pp. 273-279, ISSN 1520-5126

Tang, Z.; Kotov, N. A. (2005). One-Dimensional Assemblies of Nanoparticles: Preparation, Properties, and Promise. Advanced Materials, Vol. 17, No. 8, (April 2005), pp. 951962, ISSN 1521-4095

Van Herk, A. M. (2000). Pulsed initiation polymerization as a means of obtaining propagation rate coefficients in free-radical polymerizations. II Review up to 2000. Macromolecular Theory and Simulations, Vol. 9, No. 8, (November 2000), pp. 433-441, ISSN 1521-3919 
Videla, F. A.; Torchia, G. A.; Schinca, D. C.; Scaffardi, L. B.; Moreno, P.; Méndez, C.; Giovanetti, L. J.; Ramallo Lopez, J. M.; Roso, L. (2010). Analysis of the main optical mechanisms responsible for fragmentation of gold nanoparticles by femtosecond laser radiation. Journal of Applied Physics, Vol. 107, No. 11, (June 2010), 114308, ISSN 1089-7550

Villafiorita-Monteleone, F.; Caputo, G.; Canale, C.; Cozzoli, P. D.; Cingolani, R.; Fragouli, D.; Athanassiou, A. (2010). Light-Controlled Directional Liquid Drop Movement on TiO2 Nanorods-Based Nanocomposite Photopatterns. Langmuir, Vol. 26, No. 23, (December 2010), pp. 18557-18563, ISSN 1520-5827

Voltairas, P. A.; Fotiadis, D. I.; Michalis, L. K. (2002). Hydrodynamics of magnetic drug targeting. Journal of Biomechanics, Vol. 35, No. 6, (June 2002), pp. 813-821, ISSN 0021-9290

Wang, C.-W.; Moffit, M. G. (2004). Surface-Tunable Photoluminescence from Block Copolymer-Stabilized Cadmium Sulfide Quantum Dots. Langmuir, Vol. 20, No. 26, (December 2004), pp. 11784-11796, ISSN 1520-5827

Wang, J.; Ni, X. (2008). Interfacial structure of poly(methyl methacrylate)/ $\mathrm{TiO}_{2}$ nanocomposites prepared through photocatalytic polymerization. Journal of Applied Polymer Science, Vol. 108, No. 6, (June 2008), pp. 3552-3558, ISSN 1097-4628

Wang, M.; Singh, H.; Hatton, T.A.; Rutledge, G. C. (2004). Field-responsive superparamagnetic composite nanofibers by electrospinning. Polymer, Vol. 45, No. 16, (July 2004), pp. 5505-5514, ISSN 0032-3861

Wang, R.; Hashimoto, K.; Fujishima, A.; Chikuni, M.; Kojima, E.; Kitamura, A.; Shimohigoshi, M.; Watanabe, T. (1997). Light-induced amphiphilic surfaces. Nature, Vol. 388, No. 6641, (July 1997), pp. 431, ISSN 1476-4687

Wang, R.; Hashimoto, K.; Fujishima, A.; Chikuni, M.; Kojima, E.; Kitamura, A.; Shimohigoshi, M.; Watanabe, T. (1998). Photogeneration of Highly Amphiphilic $\mathrm{TiO}_{2}$ Surfaces. Advanced Materials, Vol. 10, No. 2, (January 1998), pp. 135-138, ISSN 1521-4095

Wang, R.; Sakai, N.; Fujishima, A.; Watanabe, T.; Hashimoto, K. (1999). Studies of Surface Wettability Conversion on $\mathrm{TiO}_{2}$ Single-Crystal Surfaces. Journal of Physical Chemistry B, Vol. 103, No. 12, (March 1999), pp. 2188-2194, ISSN 1520-5207

Weller, D.; Doerner, M. F. (2000). Extremely High-Density Longitudinal Magnetic Recording Media. Annual Review Materials Science, Vol. 30, pp. 611-644, ISSN 0084-6600

Wu, F.; Zhang, J. Z.; Kho, R.; Mehra, R. K. (2000) Radiative and Nonradiative Lifetimes of Band Edge States and Deep Trap States of CdS Nanoparticles Determined by TimeCorrelated Single Photon Counting. Chemical Physical Letters, Vol. 330, No. 3-4, (November 2000), 237-242, ISSN 0009-2614

Xia, H.; Peng, J.; Liu, K.; Li, C.; Fang, Y. (2008). Preparation and Gas Sensing Properties of Novel CdS-Supramolecular Organogel Hybrid Films. Journal of Physics D, Vol. 41, No. 10, (May 2008), 105405, ISSN 1361-6463

Yi, H.; Wu, L.-Q.; Bentley, W. E.; Ghodssi, R.; Rubloff, G. W.; Culver, J. N.; Payne, G. F. (2005). Biofabrication with chitosan. Biomacromolecules, Vol. 6, No. 6, (November 2005), pp. 2881-2894, ISSN 1525-7797

Zangmeister, R. A.; Park, J. J.; Rubloff, G. W.; Tarlov, M. J. (2006). Electrochemical study of chitosan films deposited from solution at reducing potentials. Electrochimica Acta, Vol. 51, No. 25, (July 2006), pp. 5324-5333, ISSN 0013-4686

Zhao, X.; Xu, M.; Qin, L.; Xiao, J.Q. (2007). Microstructure and magnetic properties of magnetite thin films prepared by reactive sputtering. Journal of Applied Physics, Vol. 102, No. 11, (December 2007), 113913, ISSN 1089-7550

Zhou, K.; Yin, J.-J.; Yu, L. (2006). ESR determination of the reactions between selected phenolic acids and free radicals or transition metals. Food Chemistry, Vol. 95, No. 3, (April 2006), pp. 446-457, ISSN 0308-8146 


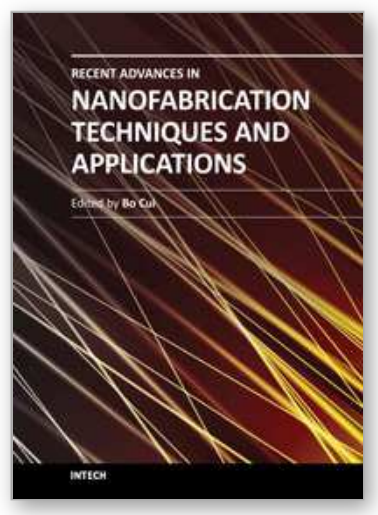

\author{
Recent Advances in Nanofabrication Techniques and Applications \\ Edited by Prof. Bo Cui
}

ISBN 978-953-307-602-7

Hard cover, 614 pages

Publisher InTech

Published online 02, December, 2011

Published in print edition December, 2011

Nanotechnology has experienced a rapid growth in the past decade, largely owing to the rapid advances in nanofabrication techniques employed to fabricate nano-devices. Nanofabrication can be divided into two categories: "bottom up" approach using chemical synthesis or self assembly, and "top down" approach using nanolithography, thin film deposition and etching techniques. Both topics are covered, though with a focus on the second category. This book contains twenty nine chapters and aims to provide the fundamentals and recent advances of nanofabrication techniques, as well as its device applications. Most chapters focus on indepth studies of a particular research field, and are thus targeted for researchers, though some chapters focus on the basics of lithographic techniques accessible for upper year undergraduate students. Divided into five parts, this book covers electron beam, focused ion beam, nanoimprint, deep and extreme UV, X-ray, scanning probe, interference, two-photon, and nanosphere lithography.

\title{
How to reference
}

In order to correctly reference this scholarly work, feel free to copy and paste the following:

Athanassia Athanassiou, Despina Fragouli, Francesca Villafiorita Monteleone, Athanasios Milionis, Fabrizio Spano, Ilker Bayer and Roberto Cingolani (2011). Laser-Based Lithography for Polymeric Nanocomposite Structures, Recent Advances in Nanofabrication Techniques and Applications, Prof. Bo Cui (Ed.), ISBN: 978953-307-602-7, InTech, Available from: http://www.intechopen.com/books/recent-advances-in-nanofabricationtechniques-and-applications/laser-based-lithography-for-polymeric-nanocomposite-structures

\section{INTECH}

open science | open minds

\section{InTech Europe}

University Campus STeP Ri

Slavka Krautzeka 83/A

51000 Rijeka, Croatia

Phone: +385 (51) 770447

Fax: +385 (51) 686166

www.intechopen.com

\section{InTech China}

Unit 405, Office Block, Hotel Equatorial Shanghai

No.65, Yan An Road (West), Shanghai, 200040, China

中国上海市延安西路65号上海国际贵都大饭店办公楼405单元

Phone: +86-21-62489820

Fax: $+86-21-62489821$ 
(C) 2011 The Author(s). Licensee IntechOpen. This is an open access article distributed under the terms of the Creative Commons Attribution 3.0 License, which permits unrestricted use, distribution, and reproduction in any medium, provided the original work is properly cited. 